\title{
Review \\ Trial Watch: Adoptive TCR-Engineered T-Cell Immunotherapy for Acute Myeloid Leukemia
}

\author{
Diana Campillo-Davo $1, * \mathbb{C}$, Sébastien Anguille ${ }^{1,2,3}$ and Eva Lion $1,2, * \mathbb{C}$ \\ 1 Laboratory of Experimental Hematology, Vaccine \& Infectious Disease Institute (VAXINFECTIO), \\ Faculty of Medicine and Health Sciences, University of Antwerp, 2610 Wilrijk, Belgium; \\ sebastien.anguille@uantwerpen.be \\ 2 Center for Cell Therapy \& Regenerative Medicine, Antwerp University Hospital, 2650 Edegem, Belgium \\ 3 Division of Hematology, Antwerp University Hospital, 2650 Edegem, Belgium \\ * Correspondence: Diana.CampilloDavo@uantwerpen.be (D.C.-D.); Eva.Lion@uantwerpen.be (E.L.); \\ Tel.: +32-3821-5254 (D.C.-D.); +32-3821-4112 (E.L.)
}

Citation: Campillo-Davo, D.; Anguille, S.; Lion, E. Trial Watch: Adoptive TCR-Engineered T-Cell Immunotherapy for Acute Myeloid Leukemia. Cancers 2021, 13, 4519. https://doi.org/10.3390/ cancers13184519

Academic Editors: Bruno Quesnel and François Guilhot

Received: 5 May 2021

Accepted: 1 September 2021

Published: 8 September 2021

Publisher's Note: MDPI stays neutral with regard to jurisdictional claims in published maps and institutional affiliations.

Copyright: (c) 2021 by the authors. Licensee MDPI, Basel, Switzerland. This article is an open access article distributed under the terms and conditions of the Creative Commons Attribution (CC BY) license (https:// creativecommons.org/licenses/by/ $4.0 /)$.
Simple Summary: Acute myeloid leukemia (AML) is a type of blood cancer with an extremely grim prognosis. This is due to the fact that the majority of patients will relapse after frontline treatment. Overall survival of relapsed AML is very low, and treatment options are few. T lymphocytes harnessed with antitumor T-cell receptors (TCRs) can produce objective clinical responses in certain cancers, such as melanoma, but have not entered the main road for AML. In this review, we describe the current status of the field of TCR-T-cell therapies for AML.

Abstract: Despite the advent of novel therapies, acute myeloid leukemia (AML) remains associated with a grim prognosis. This is exemplified by 5 -year overall survival rates not exceeding $30 \%$. Even with frontline high-intensity chemotherapy regimens and allogeneic hematopoietic stem cell transplantation, the majority of patients with AML will relapse. For these patients, treatment options are few, and novel therapies are urgently needed. Adoptive T-cell therapies represent an attractive therapeutic avenue due to the intrinsic ability of $\mathrm{T}$ lymphocytes to recognize tumor cells with high specificity and efficiency. In particular, T-cell therapies focused on introducing T-cell receptors (TCRs) against tumor antigens have achieved objective clinical responses in solid tumors such as synovial sarcoma and melanoma. However, contrary to chimeric antigen receptor (CAR)-T cells with groundbreaking results in B-cell malignancies, the use of TCR-T cells for hematological malignancies is still in its infancy. In this review, we provide an overview of the status and clinical advances in adoptive TCR-T-cell therapy for the treatment of AML.

Keywords: T-cell receptor; TCR engineering; adoptive T-cell therapy; acute myeloid leukemia

\section{Introduction}

Acute myeloid leukemia (AML) is a type of blood cancer that carries a grim prognosis, despite considerable therapeutic advances in the last decade. Current treatment of newly diagnosed AML generally consists of intensive chemotherapy (IC) followed by allogeneic hematopoietic stem cell transplantation (allo-HSCT) in younger and fit patients, and lowintensity chemotherapy (e.g., hypomethylating agents) combined with-depending on the availability of the drug-the oral BCL-2 inhibitor venetoclax in older and/or less fit patients. Allo-HSCT, which is considered an immunotherapeutic strategy, since part of its mode of action involves the administration of T-lymphocytes that can recognize and eliminate the leukemic cells, is the gold standard post-remission treatment in AML. As discussed above, it is generally reserved for younger patients. Only a small population of elderly AML patients actually receives allo-HSCT [1]. Nevertheless, even with allo-HSCT, the majority of AML patients will relapse, explaining the poor 5-year overall survival rate of only $30 \%$ [2]. This explains why there is still a high unmet need to treat relapsed (or refractory) disease or 
to prevent relapse by strategies aimed at eradication of measurable residual disease (MRD; known before as minimal residual disease), which is the primary cause of relapse [3,4].

It is within this context that immunotherapy comes to the fore. So far, most clinical trials with immunotherapies in AML have focused on monoclonal antibodies or checkpoint inhibitors. Cell-based immunotherapies for AML, except for allo-HSCT, are still experimental and have not yet surpassed the clinical trial stage [5]. Among the cell therapies that are currently being studied in AML are dendritic cells (DC) loaded with leukemia-associated antigens to stimulate anti-leukemia (T-cell) immunity; DC "vaccination" has shown promising results, especially as maintenance therapy in a low-disease burden setting [6]. Still in their infancy but promising are clinical trials that explore adoptive cell therapy (ACT) with leukemia-reactive T lymphocytes. AML cells are known to express a broad range of tumor antigens, including - but not limited to-overexpressed leukemia-associated antigens (LAAs), leukemia-specific antigens (LSAs) or neoantigens and cancer-testis antigens (reviewed by $[7,8]$ ). Target antigens are either molecules expressed on the surface ("extracellular") or internally processed ("intracellular") proteins that are present on the AML surface in the form of peptides bound to human leukocyte antigen (HLA)/major histocompatibility complex (MHC) molecules, which can be recognized by $\mathrm{T}$ cells via their T-cell receptor (TCR) (Figure 1). Surface ("extracellular") antigens are targeted by chimeric antigen receptor (CAR) T-cell therapy. This form of therapy, which involves the adoptive transfer of lymphocytes genetically modified to express a CAR, has become an established treatment option in different hematological malignancies [9-11]. CAR-T-cell therapy has also been aimed at treating AML (reviewed by [12-14]). The first clinical report of CAR-Tcell therapy in AML dates back to 2013; in that study, a second-generation CAR against Lewis $\mathrm{Y}$ antigen showed limited clinical efficacy, but showed T-cell biological activity in terms of trafficking to the BM and in vivo persistence without hematopoietic toxicity [15]. Other target antigens in anti-AML CAR T-cell therapy include CD33, CD123, and C-type lectin-like molecule-1 (CLL-1) [16]. Unfortunately, most of the "extracellular" target antigens in AML are also expressed on normal hematopoietic cells, posing an important barrier to the applicability of CAR-T-cell therapies in AML.

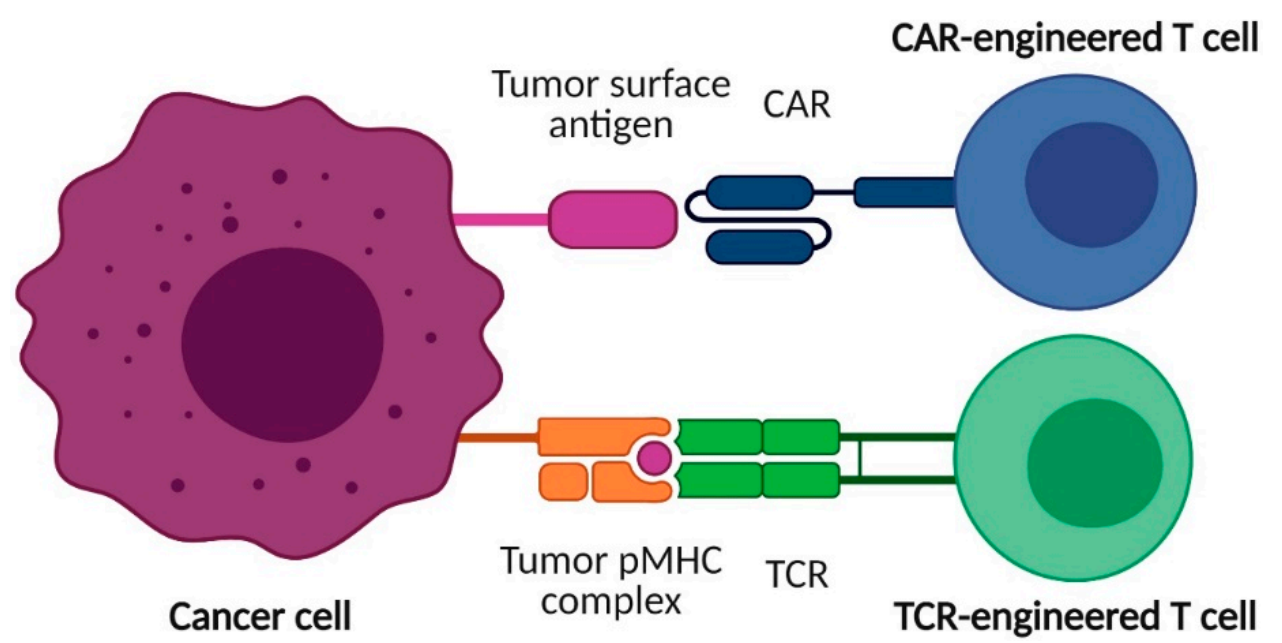

Figure 1. Chimeric antigen receptor (CAR) and T-cell receptor (TCR) engineered T cells. CAR-T cells usually target surface antigens, whereas TCR-T cells recognize internally processed proteins presented by molecules of the major histocompatibility complex (MHC) as peptide-MHC (pMHC) complexes. Each TCR is specific for a pMHC, allowing an infinite set of pMHC combinations that can be exploited for TCR-T-cell therapy. Created with BioRender.com (San Francisco, CA, USA).

Although intracellular antigens can also be targeted by CARs using antibodies recognizing peptide-MHC (pMHC) complexes [17], traditionally, this has been the role of TCRs. Thus, in TCR-T-cell therapies, and similar to CAR-T-cell therapies, lymphocytes for adoptive transfer are genetically engineered with tumor antigen-specific TCRs to redi- 
rect their specificity towards pMHC complexes (reviewed by [18] in solid tumors and by $[19,20]$ in hematological malignancies). Conventional $\alpha \beta$ T cells are the most frequent TCR-engineered cell type. More recently, other lymphocytes, such as $\gamma \delta$ T cells, have garnered attention due to their excellent natural antitumor properties that can be exploited as cellular immunotherapy [21]. $\gamma \delta \mathrm{T}$ cells are a subset of unconventional T cells that express $\gamma \delta$ TCRs instead of $\alpha \beta$ TCRs and compose up to $10 \%$ of peripheral T cells [22]. Despite the low frequency in peripheral blood, these cells can be easily expanded ex vivo [23]. Given the numerous intracellular antigens identified in AML and the presence of leukemiaassociated surface antigens in healthy cells [7,8], AML might be more suited for TCR-T-cell therapies. Moreover, compared to CARs, TCRs also require lower epitope densities to function [24]. Although there are certain drawbacks to the use of TCR-T cells, including their HLA restriction, which limits their broad applicability, TCR-based T-cell therapies have produced encouraging results, especially in patients with melanoma and certain other solid tumors [24]. In this review, we summarize the status and clinical advances in the use of TCR-engineered T cells for the treatment of AML.

\section{Target Antigens in TCR-T-Cell Therapies for AML}

Cancer immunotherapies using TCR-T cells require TCRs that recognize tumor antigens in a specific manner [25]. Currently, Wilms' tumor 1 (WT1), preferentially expressed antigen in melanoma (PRAME), and minor histocompatibility antigens (MiHA) have been the only AML antigens targeted using TCR-T cells in a clinical setting.

\subsection{WT1}

WT1 is a zinc-finger translation factor that is overexpressed in AML and other hematological and solid malignancies [26]. It is mainly found in the cytoplasm of tumor cells $[27,28]$, whereas in leukemic cells, it is more frequently found in the nuclei $[27,29]$, although it can shuttle between the nucleus and cytoplasm [30]. In AML, WT1 overexpression occurs in 73-93\% of patients at diagnosis (reviewed by [31]). Although other markers and techniques are preferred for MRD measurement (reviewed by [3,4]), WT1 messenger RNA (mRNA) levels can be used as a marker for MRD and a prognostic factor for relapse in AML if no other markers are available [31]. Somatic WT1 mutations occur in approximately 6-15\% of AML patients at diagnosis (reviewed by [32]) and are more frequent at a younger age and in cytogenetically normal AML (CN-AML) patients [31,32], which account for $40-50 \%$ of AML patients [33,34]. WT1 aberrations usually occur in exons 1,7 , and 9 , primarily creating premature stop codons and frameshift mutations affecting the reading frame [32]. These mutations appear to confer a negative prognostic outcome by increasing the risk of relapse and death.

\subsection{PRAME}

PRAME is a repressor of the retinoic acid receptor [35]. Similar to WT1, PRAME is also overexpressed in different cancer types, including AML [36]. Approximately 30-87\% of patients at diagnosis overexpress PRAME mRNA [36-38], and, as with WT1, it could be used as a surrogate marker of MRD in AML [37]. Combined detection of WT1 and PRAME has been suggested to be a sensitive molecular biomarker for monitoring MRD in AML [39]. CD8 T-cell responses against WT1 and PRAME are detected in healthy individuals and AML patients [40-43]. More importantly, multi-epitope WT1-specific and PRAME-specific T-cell reactivities have also been confirmed in clinical studies after vaccination with WT1-loaded DC [44] or PRAME peptide vaccination [45].

\section{3. $\mathrm{MiHA}$}

MiHA antigens are polymorphic peptides presented by HLA molecules, resulting from the degradation of proteins from polymorphic genes with single-nucleotide polymorphisms, base-pair insertions or deletions, or copy number variations [46]. In cancer therapy, allogeneic T cells from an HLA-matched donor-administered in the setting of allo-HSCT 
or donor lymphocyte infusions-can recognize mismatched MiHA in the recipient patient [46]. When this recognition occurs against MiHA expressed by the leukemic cells, donor T cells induce graft-versus-leukemia (GVL) processes; however, if the polymorphic peptide is also expressed in normal cells, undesirable graft-versus-host disease (GVHD) can also occur [46]. In hematological malignancies, donor $\mathrm{T}$ cells from donor lymphocyte infusions targeting the ubiquitously expressed MiHA peptides can induce complete remissions by GVL, albeit frequently accompanied by concurrent GVHD [47]. In contrast, $\mathrm{T}$ cells recognizing hematopoiesis-restricted MiHA peptides, i.e., only expressed in cells of hematopoietic origin, such as HA-1 and HA-2, can lead to complete remissions in leukemia patients that relapsed after receiving allo-HSCT by inducing GVL without severe GVHD [47]. This nonameric peptide has two allelic variants codified on chromosome 9, $\mathrm{HA}-1 \mathrm{H}$ and HA-1R, which vary in one single amino acid [48]. Both variants are able to bind HLA-A*02:01 molecules; however, only HA-1H can effectively be expressed on the cell membrane by HLA-A*02:01 and induce T-cell responses in HA-1 R/R homozygous individuals [48,49]. HA-1H variant, which is present in $30 \%$ of the population [49], can also be presented by HLA-A*02:06 [50].

\section{Characteristics and Results of Clinical Trials Using AML-Directed TCR-T Cells}

Currently, there are 12 early phase clinical trials with TCR-T cells against relapsed/ refractory $(\mathrm{R} / \mathrm{R}) \mathrm{AML}$, focusing on investigating the feasibility and safety of the therapy (Tables 1-4). So far, 38 AML patients have been treated out of 57 hematological cancer patients recruited, and approximately 250 patients are intended to be recruited in total (status of trials listed in Table 1). Most of these clinical trials genetically engineer conventional autologous T cells with $\alpha \beta$ TCRs to target WT1, PRAME, and MiHA in the context of HLA-A*02:01 restriction, which is expressed in approximately $50 \%$ of the European population (characteristics of T-cell products are listed in Table 2).

Five studies have focused on targeting WT1, of which three have been recently completed. Two of these three completed clinical trials (clinicaltrials.gov identifier: NCT01621724, NCT02550535) used escalating doses of HLA-A*02:01-restricted WT1-specific TCR-T cells (patient characteristics and treatment regimens are listed in Table 3) [51-53]. In both cases, single doses of either $2 \times 10^{7} \mathrm{TCR}-\mathrm{T}$ cells $/ \mathrm{kg}$ or $1 \times 10^{8} \mathrm{~T}$ cells $/ \mathrm{kg}$ were administered per cohort, accompanied by an injection of interleukin (IL)-2. In NCT01621724, WT1-specific T cells persisted one year after infusion in four out of a total of seven patients with AML and chronic myeloid leukemia (CML) (outcomes of clinical trials using TCR-T cells for AML are listed in Table 4) [51]. Complete responses were also observed in four out of seven patients; however, it is unclear whether those with complete responses presented persistent WT1-specific T cells in peripheral blood. In NCT02550535, a total of six AML patients, three patients with myelodysplastic syndrome (MDS), and a patient with tyrosine kinase inhibitor-resistant CML were treated with a WT1 $126-134$-specific TCR-T-cell product $[52,53]$. AML patients in complete morphological remission before treatment were administered a single dose of TCR-T cells accompanied with IL-2. TCR-T cells proliferated in vivo and were detectable 28 days following infusion in all patients. Median overall survival (OS) of AML patients following treatment with TCR-T cells was 12 months. It remains unclear whether patients with the highest median OS received the highest dose in the trial or not. In both studies, TCR-T-cell products were generally well tolerated. No adverse effects were observed, except a case of febrile neutropenia and cytokine release syndrome that was successfully treated.

While the HLA-A*02:01 allele is one the most frequent HLA class I types in European and North American populations, HLA-A*24:02 is the most common HLA-A allele in Japan. Therefore, the third completed phase I dose-escalation trial conducted in Japanese individuals focused on administering two rounds of an HLA-A*24:02-restricted WT1 ${ }_{235-243}$ peptide-specific TCR to HLA-A*24:02-positive patients, followed by WT1 peptide vaccination (umin.ac.jp Identifier: UMIN000011519; [54]). In these three completed studies, TCR-T-cell treatment was well tolerated, with no dose-limiting toxicities related to treat- 
ment; however, one instance of cytokine release syndrome was reported, possibly related to treatment (Table 4). TCR-T-cell treatment was well tolerated, with seven out of eight patients showing no or only grade 1 adverse events. Observed adverse events were mostly related to peptide vaccination at the site of injection. WT1-specific TCR-T cells were successfully detected in the peripheral blood of eight treated patients. More importantly, TCR-T cells were still detectable 8 weeks post-administration in five of the eight treated patients. The number of circulating TCR-T cells positively correlated with the number of cells administered, especially during the first 14 days after treatment. WT1-specific TCR-T cells from one patient responded to $W T 1_{235-243}$ peptide, indicating that TCR-T-cell antitumor activity was still intact despite decreasing circulating T-cell numbers. A transient decrease in peripheral blood or BM blasts was observed in three cases after treatment, whereas the disease progressed in four patients. Median OS was 15.9 months, with four out of five patients with persistent $\mathrm{T}$ cells surviving longer than 12 months, compared to only one out of three patients without detectable engineered $\mathrm{T}$ cells surviving beyond 12 months. Further studies including more patients would be needed to completely ascertain the hematologic benefit of these WT1-specific TCR-T cells, especially since T cells were engineered with a TCR with a physiological affinity. It is also important to note that patients with decreasing blast numbers in BM after treatment were those with a higher percentage of WT1-specific TCR-T cells in the T-cell product. Therefore, achieving sufficient TCR-engineered T cells in the medicinal product is crucial in this type of therapy. Two other studies focusing on WT1 are still ongoing in the United States of America (USA; Table 1; NCT01640301 and NCT02770820) [55,56]. Both are centered on high-risk AML and use the

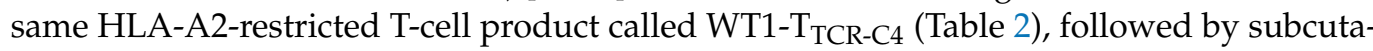
neous injection of IL-2 (Table 3). Preliminary results from 12 treated patients (NCT01640301) indicate that treatment was generally well tolerated (Table 4) [55]. GVHD was observed in some patients, including a case of grade 3 acute GVHD; however, since the onset of GVHD events occurred at a median of 123 days after infusion, GVHD was likely not caused by the T-cell product. TCR-T cells persisted in $75 \%$ of patients until day 28 post-administration and were detected after 12 months in 33\% of patients. More importantly, clinical efficacy following WT1-specific TCR-T-cell treatment was demonstrated by a relapse-free survival (RFS) of $100 \%$ at a median of 44 months, which was significantly higher than a comparable group of high-risk AML patients that did not receive TCR-T-cell therapy [55]. Results from trial number NCT02770820 regarding the persistence of T cells and disease response are currently not available. Preliminary data on adverse events indicate that TCR-T cells were well tolerated, with no severe adverse effects (Table 4) [56]. Only four out of seven patients completed treatment. One patient died during treatment; however, due to the absence of data on the cause of death, it is difficult to determine whether it was related to treatment or not.

With regard to PRAME-specific TCR-T cells, two different trials are ongoing for relapsed AML in the context of HLA-A2 restriction (Table 1). Both NCT02743611 and EudraCT-2017-000440-18 trials are analyzing increasing doses of autologous TCR-T-cell products (BPX-701 and MDG1011, respectively) up to $5 \times 10^{6} \mathrm{~T}$ cells $/ \mathrm{kg}$ (Tables 2 and 3) [57]. In addition, in a third clinical study (EudraCT-2018-000717-20), patients enrolled in trial EudraCT-2017-000440-18 will be followed up for up to 14 years. Results from these clinical trials are pending and will provide the field with information about the future of PRAMEspecific TCR-T-cell therapies in AML.

Two studies carried out in the Netherlands and one in the USA have targeted MiHA HA-1H peptide following allo-HSCT (Table 1). In the completed study (EudraCT-2010024625-20), donor-derived Epstein-Barr virus (EBV) and/or cytomegalovirus (CMV)specific T cells were engineered with an HLA-A*02:01-restricted MiHA HA-1H peptidespecific TCR $[49,58]$, which contained an additional disulfide bond to improve TCR pairing and stability, in which the sequence was codon optimized [59]. Donor-derived EBV- or CMV-specific T cells can be safely used for adoptive transfer because (i) the reactivity of these T cells is known, (ii) these T cells help to prevent EBV and CMV infections, and (iii) 
they do not induce GVHD (Figure 2) [55,58,60]. A drawback of this strategy is that patients may not be seropositive for EBV and CMV. Even if they are, sufficient T cells for TCR-T-cell development may not be available when using autologous EBV- or CMV-specific T cells. As illustrated in EudraCT-2010-024625-20, in nine recruited patients, only two were EBV and CMV seropositive [49]. Moreover, although seven donors were EBV seropositive, HA-1H TCR-transduced CMV or EBV-specific T cells could be produced in five individuals [49]. Four out of five treated patients received two administrations of engineered $\mathrm{T}$ cells. TCR-transduced donor-derived EBV-specific T cells were well tolerated, with no toxicities related to treatment nor GVHD [49]. A study conducted in the Netherlands is currently investigating this strategy (trialregister.nl identifier: NTR6541). The T-cell product called TEG001 is based on retroviral transduction of a high-affinity V $\gamma 9 \mathrm{~V} \delta 2 \mathrm{TCR}$ derived from the natural repertoire of a healthy individual [61,62]. Although there are no clinical results available, a preclinical in vivo evaluation of TEG001 demonstrated that TEG001 eradicated primary AML blasts [63]. More importantly, after administration, TEG001 persisted up to 50 days in mice but did not target human cord blood-derived healthy hematopoietic cells.

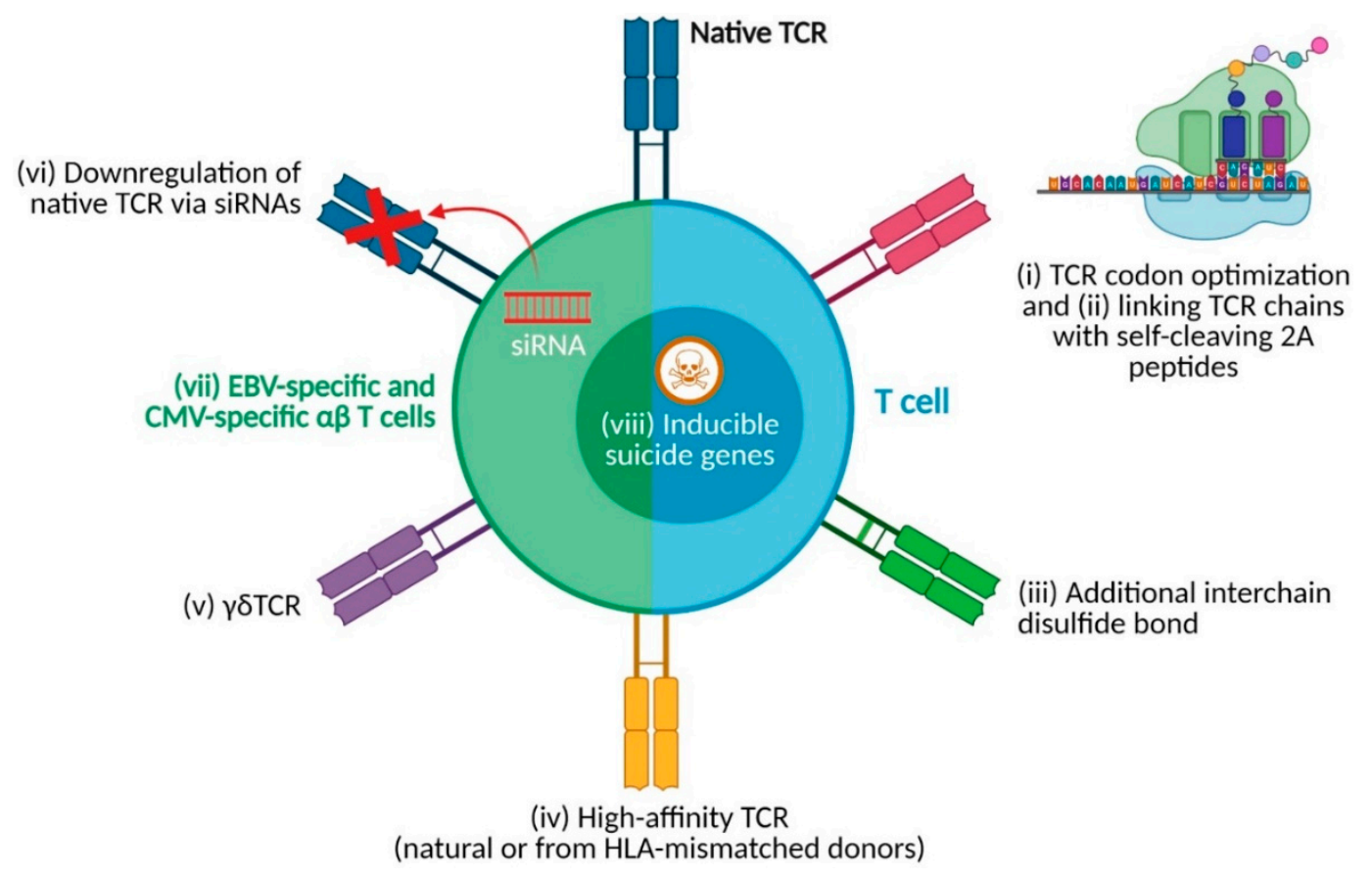

Figure 2. TCR-directed optimization strategies that have been clinically tested in AML. Different strategies to enhance TCRT-cell therapies have been used in clinical trials for the treatment of AML. These include (i) codon optimization of transgenic TCR sequences to improve protein translation; (ii) linking transgenic TCR alpha and beta chains via self-cleaving $2 \mathrm{~A}$ peptides for equimolar expression of TCR chains; (iii) addition of cysteine residues that bind covalently to provide a second interchain disulfide bond and improve pairing of transgenic TCR chains; (iv) usage of high-affinity TCRs, either derived from normal TCR repertoires after screening of multiple TCR candidates or from HLA-mismatched donors to generate allo-restricted TCRs, to enhance antigen recognition; (v) TCR-engineering with $\gamma \delta \mathrm{TCRs}$ derived from $\gamma \delta$ T cell clones, or (vi) downregulation of native TCR chains via introduction of small interfering "silencing" RNAs (siRNAs) targeting native TCR transcripts to prevent TCR mispairing; (vii) usage of autologous donor-derived Epstein-Barr virus (EBV) and cytomegalovirus (CMV)-specific T cells to prevent EBV and CMV infections and graft-versus-host disease in TCR-T-cell treated patients; and (viii) introduction of inducible suicide genes that would allow the elimination of TCR-engineered T cells in case of treatment-related toxicities. Created with BioRender.com. 
Table 1. Clinical trials using TCR-T cells for AML.

\begin{tabular}{|c|c|c|c|c|c|c|c|}
\hline $\begin{array}{l}\text { Clinical Trial } \\
\text { Identifier }\end{array}$ & Location & $\begin{array}{c}\text { Status } \\
\text { (First Posted) }\end{array}$ & Phase & AML Status & $\begin{array}{c}\text { Prior } \\
\text { Treatment }\end{array}$ & $\begin{array}{l}\text { AML Patients Recruited or } \\
\text { Treated (Intended) }\end{array}$ & Ref. \\
\hline \multicolumn{8}{|l|}{ WT1-Specific } \\
\hline $\begin{array}{l}\text { NCT01621724 } \\
\text { EudraCT-2006- } \\
\quad 004950-25\end{array}$ & UK & $\begin{array}{c}\text { Completed } \\
(2012, \text { completed in 2018) }\end{array}$ & $\mathrm{I} / \mathrm{II}$ & AML & n.d. & 7 treated $(18)$ & [51] \\
\hline $\begin{array}{l}\text { NCT02550535 } \\
\text { EudraCT-2014- } \\
\text { 003111-10 }\end{array}$ & $\begin{array}{l}\text { Belgium } \\
\text { Germany } \\
\text { UK }\end{array}$ & $\begin{array}{c}\text { Completed } \\
(2015, \text { completed in 2018) }\end{array}$ & $\mathrm{I} / \mathrm{II}$ & $\begin{array}{l}\text { Relapsed/ } \\
\text { stable AML }\end{array}$ & HAT & $\begin{array}{c}10 \text { pt. treated: } 6 \text { AML, } 3 \\
\text { MDS and } 1 \text { TKI- resistant } \\
\text { CML (25-30) }\end{array}$ & {$[52,53]$} \\
\hline UMIN000011519 & Japan & $\begin{array}{c}\text { Completed } \\
(2013, \text { completed in 2018) }\end{array}$ & I & $\mathrm{R} / \mathrm{R} \mathrm{AML}$ & n.d. & $\begin{array}{l}12 \text { recruited, } \\
8 \text { treated }\end{array}$ & [54] \\
\hline NCT01640301 & USA & $\begin{array}{l}\text { Active, not recruiting } \\
\text { (2012) }\end{array}$ & I/II & $\begin{array}{l}\text { High-risk/ } \\
\text { relapsed AML }\end{array}$ & allo-HSCT & 12 treated $(45)$ & [55] \\
\hline NCT02770820 & USA & $\begin{array}{l}\text { Active, not recruiting } \\
\text { (2016) }\end{array}$ & $\mathrm{I} / \mathrm{II}$ & $\begin{array}{l}\text { High-risk } \\
\text { non-M3 AML }\end{array}$ & $\begin{array}{l}\text { Consolidation } \\
\text { chemotherapy }\end{array}$ & 7 treated (9) & [56] \\
\hline \multicolumn{8}{|l|}{ PRAME-Specific } \\
\hline NCT02743611 & USA & $\begin{array}{l}\text { Active, not recruiting } \\
\text { (2016) }\end{array}$ & I/II & Relapsed AML & n.d. & $(28)$ & [57] \\
\hline $\begin{array}{l}\text { NCT03503968 } \\
\text { EudraCT-2017- } \\
\text { 000440-18 }\end{array}$ & Germany & Recruiting (2018) & I/II & R/R AML & $\begin{array}{l}\text { HAT and/or } \\
\text { allo-HSCT }\end{array}$ & $(92)$ & n.d. \\
\hline $\begin{array}{l}\text { EudraCT-2018- } \\
000717-20\end{array}$ & Germany & Ongoing (2019) & $\begin{array}{l}\text { Long-term } \\
\text { follow-up of } \\
\text { phase I }\end{array}$ & $\mathrm{R} / \mathrm{R} \mathrm{AML}$ & $\begin{array}{l}\text { HAT and/or } \\
\text { allo-HSCT }\end{array}$ & $(52)$ & n.d. \\
\hline \multicolumn{8}{|c|}{ MiHA HA-1H-Specific } \\
\hline $\begin{array}{c}\text { EudraCT-2010- } \\
\text { 024625-20 } \\
\text { NTR3454/NL3307 }\end{array}$ & Netherlands & $\begin{array}{c}\text { Completed } \\
(2012, \text { prematurely ended } \\
\text { in 2018) }\end{array}$ & I & $\begin{array}{l}\text { High-risk } \\
\text { AML }\end{array}$ & allo-HSCT & $\begin{array}{l}9 \text { recruited, } \\
5 \text { treated }(20)\end{array}$ & {$[49,58]$} \\
\hline $\begin{array}{l}\text { NCT04464889 } \\
\text { EudraCT-2019- } \\
002346-20\end{array}$ & Netherlands & $\begin{array}{l}\text { Active, not recruiting } \\
(2020)\end{array}$ & I & R/R AML & allo-HSCT & $(29)$ & n.d. \\
\hline NCT03326921 & USA & Recruiting (2017) & I & $\begin{array}{l}\text { Recurrent } \\
\text { AML }\end{array}$ & allo-HSCT & $(24)$ & n.d. \\
\hline \multicolumn{8}{|l|}{ Other } \\
\hline NTR6541/NL6357 & Netherlands & Recruiting (2017) & I & R/R AML & n.d. & (18) & [61-63] \\
\hline
\end{tabular}

Abbreviations: allo-HSCT, allogeneic hematopoietic stem cell transplantation; AML, acute myeloid leukemia; CML, chronic myeloid leukemia; HAT, hypomethylating agent therapy; MDS, myelodysplastic syndrome; MiHA, minor histocompatibility antigen; n.d., no data; PRAME, preferentially expressed antigen in melanoma; R/R, relapsed/refractory; TKI, tyrosine kinase inhibitors; UK, United Kingdom; USA, United States of America; WT1, Wilms' tumor 1. Last search on 25 July 2021.

Table 2. Characteristics of T-cell products.

\begin{tabular}{|c|c|c|c|c|c|}
\hline \multirow{2}{*}{$\begin{array}{l}\text { Clinical Trial } \\
\text { Identifier }\end{array}$} & \multirow{2}{*}{$\begin{array}{l}\text { Name of } \\
\text { T-Cell Product }\end{array}$} & \multicolumn{2}{|r|}{ TCR } & \multirow{2}{*}{$\begin{array}{c}\text { T-Cell } \\
\text { Population }\end{array}$} & \multirow{2}{*}{ Ref. } \\
\hline & & Restriction & High-Affinity/Avidity & & \\
\hline \multicolumn{6}{|l|}{ WT1-Specific } \\
\hline $\begin{array}{c}\text { NCT01621724 } \\
\text { EudraCT-2006-004950-25 }\end{array}$ & $\begin{array}{c}\text { WT1 } \\
\text { TCR-001 }\end{array}$ & HLA-A2 & n.d. & Autologous T cells & [51] \\
\hline $\begin{array}{l}\text { NCT02550535 } \\
\text { EudraCT-2014-003111-10 }\end{array}$ & n.d. & HLA-A2 & n.d. (allo-restricted TCR) & Autologous T cells & {$[52,53]$} \\
\hline UMIN000011519 & n.d. & HLA-A24 & No & Autologous T cells & {$[54]$} \\
\hline NCT01640301 & $\mathrm{WT} 1-\mathrm{T}_{\mathrm{TCR}-\mathrm{C} 4}$ & HLA-A2 & Yes (from healthy individual) & $\begin{array}{c}\text { Donor-derived } \\
\text { EBV-specific CD8 T cells }\end{array}$ & [55] \\
\hline NCT02770820 & $\mathrm{WT} 1-\mathrm{T}_{\mathrm{TCR}-\mathrm{C} 4}$ & HLA-A2 & Yes (from healthy individual) & $\begin{array}{c}\text { Autologous central } \\
\text { memory/naïve CD8 T } \\
\text { cells EBV-specific T cells }\end{array}$ & {$[56]$} \\
\hline
\end{tabular}


Table 2. Cont.

\begin{tabular}{|c|c|c|c|c|c|}
\hline \multirow{2}{*}{$\begin{array}{l}\text { Clinical Trial } \\
\text { Identifier }\end{array}$} & \multirow{2}{*}{$\begin{array}{c}\text { Name of } \\
\text { T-Cell Product }\end{array}$} & \multicolumn{2}{|r|}{ TCR } & \multirow{2}{*}{$\begin{array}{c}\text { T-Cell } \\
\text { Population }\end{array}$} & \multirow{2}{*}{ Ref. } \\
\hline & & Restriction & High-Affinity/Avidity & & \\
\hline \multicolumn{6}{|l|}{ PRAME-specific } \\
\hline NCT02743611 & BPX-701 & HLA-A2 & Yes (allo-restricted donor) & Autologous T cells & [57] \\
\hline $\begin{array}{c}\text { NCT03503968 } \\
\text { EudraCT-2017-000440-18 } \\
\end{array}$ & MDG1011 & HLA-A2 & n.d. & Autologous T cells & n.d. \\
\hline EudraCT-2018-000717-20 & MDG1011 & HLA-A2 & n.d. & Autologous T cells & n.d. \\
\hline \multicolumn{6}{|l|}{ MiHA HA-1H-specific } \\
\hline $\begin{array}{l}\text { EudraCT-2010-024625-20 } \\
\text { NTR3454/NL3307 }\end{array}$ & n.d. & HLA-A2 & n.d. & $\begin{array}{c}\text { Autologous } \\
\text { donor-derived CMV- } \\
\text { and/or EBV-specific T } \\
\text { cells }\end{array}$ & {$[49,58]$} \\
\hline $\begin{array}{c}\text { NCT04464889 } \\
\text { EudraCT-2019-002346-20 }\end{array}$ & MDG1021 & HLA-A2 & n.d. & Autologous T cells & n.d. \\
\hline NCT03326921 & n.d. & HLA-A2 & n.d. & $\begin{array}{l}\text { CD4 and CD8 memory } \\
\text { donor T cells }\end{array}$ & n.d. \\
\hline \multicolumn{6}{|l|}{ Other } \\
\hline NTR6541/NL6357 & TEG001 & $\begin{array}{c}\text { n.a. }(\mathrm{V} \gamma 9 \mathrm{~V} \delta 2 \\
\text { TCR) }\end{array}$ & Yes & Autologous T cells & [61-63] \\
\hline
\end{tabular}

Abbreviations: CMV, cytomegalovirus; EBV, Epstein-Barr virus; HA-1H, HLA-A*02:01-restricted minor histocompatibility antigen 1 peptide variant $\mathrm{H}$; HLA, human leukocyte antigen; HLA-A2, HLA-A*02:01; HLA-A24, HLA-A*24:02; MiHA, minor histocompatibility antigen; n.a., not applicable; n.d., no data; PRAME, preferentially expressed antigen in melanoma; TCR, T-cell receptor; WT1, Wilms' tumor 1. Last search on 25 July 2021.

Table 3. Patient characteristics and treatment regimens.

\begin{tabular}{|c|c|c|c|c|c|}
\hline $\begin{array}{l}\text { Clinical Trial } \\
\text { Identifier }\end{array}$ & Age of Patients & $\begin{array}{l}\text { No. Patients per } \\
\text { Arm or Cohort }\end{array}$ & Dosage per Cohort & $\begin{array}{l}\text { Additional } \\
\text { Treatments }\end{array}$ & Ref. \\
\hline \multicolumn{6}{|l|}{ WT1-Specific } \\
\hline $\begin{array}{c}\text { NCT01621724 } \\
\text { EudraCT-2006-004950-25 }\end{array}$ & $\begin{array}{l}1 \text { pt. } 18-64 \text { years } \\
6 \text { pt. } \geq 65 \text { years }\end{array}$ & $\begin{array}{l}\text { Cohort 1: } 3 \text { pt. } \\
\text { Cohort 2: } 4 \text { pt. }\end{array}$ & $\begin{array}{l}\text { Cohort } 1: \leq 2 \times 10^{7} \mathrm{~T} \text { cells } / \mathrm{kg} \\
\text { Cohort } 2: \leq 1 \times 10^{8} \mathrm{~T} \text { cells } / \mathrm{kg}\end{array}$ & $\begin{array}{l}\text { Standard } \\
\text { conditioning; } \\
10^{6} \text { units } / \mathrm{m}^{2} \text { IL-2 }\end{array}$ & [51] \\
\hline $\begin{array}{c}\text { NCT02550535 } \\
\text { EudraCT-2014-003111-10 }\end{array}$ & n.d. & $\begin{array}{c}\text { Cohort } 1: 7 \mathrm{pt} \text {. } \\
\text { Cohort 2: } 3 \text { pt. } \\
\text { (6 AML, } 3 \text { MDS and } 1 \text { TKI- } \\
\text { resistant CML in total) }\end{array}$ & $\begin{array}{l}\text { Cohort } 1: \leq 2 \times 10^{7} \mathrm{~T} \text { cells } / \mathrm{kg} \\
\text { Cohort } 2: \leq 1 \times 10^{8} \mathrm{~T} \text { cells } / \mathrm{kg}\end{array}$ & $\begin{array}{l}\text { Subcutaneous low- } \\
\text { dose injections of IL-2 } \\
\left(1 \times 10^{6} \text { units } / \mathrm{m}^{2}\right)\end{array}$ & {$[52,53]$} \\
\hline UMIN000011519 & $\begin{array}{l}1 \text { pt. } 18-64 \text { years } \\
7 \text { pt. } \geq 65 \text { years }\end{array}$ & $\begin{array}{c}\text { Cohort } 1: 3 \text { pt. } \\
\text { (1 AML and } 2 \text { MDS) } \\
\text { Cohort 2: } 3 \text { pt. (MDS) } \\
\text { (+2 pt. extracohort; } \\
1 \text { AML and } 1 \text { MDS) } \\
\text { Cohort } 3: 0 \text { pt. }\end{array}$ & $\begin{array}{l}\text { Cohort 1: two doses of } 2 \times 10^{8} \text { cells } \\
\text { Cohort 2: two doses of } 1 \times 10^{9} \text { cells } \\
\text { Cohort 3: two doses of } 5 \times 10^{9} \text { cells } \\
\text { Cells administered at day } 0 \text { and } 28\end{array}$ & $\begin{array}{c}\text { Subcutaneous } \\
\text { injection of } 300 \mu \mathrm{g} \\
\text { mutated } W T 1_{235-243} \\
\text { peptide at day } 30 \\
\text { and } 44\end{array}$ & [54] \\
\hline NCT01640301 & $\begin{array}{l}8 \text { pt } 18-64 \text { years } \\
4 \text { pt. } \geq 65 \text { years }\end{array}$ & $\begin{array}{l}\text { Treatment arm: } 12 \mathrm{pt} . \\
\text { Prophylactic arm: } 12 \mathrm{pt}\end{array}$ & $\begin{array}{l}\text { 12/12 pt.; one dose of } 10^{10} \mathrm{~T} \text { cells } / \mathrm{m}^{2} \\
7 / 12 \mathrm{pt} \text {; second dose of } 10^{10} \mathrm{~T} \text { cells } / \mathrm{m}^{2} \\
\text { (administered if frequency of TCR-T cells } \\
\text { was }<3 \% \text { of total peripheral CD }+\mathrm{T} \text { cells) }\end{array}$ & $\begin{array}{l}\text { Subcutaneous } \\
\text { low-dose injection } \\
\text { of IL-2 }\end{array}$ & [55] \\
\hline NCT02770820 & $\begin{array}{l}4 \text { pt. } 18-64 \text { years } \\
3 \text { pt. } \geq 65 \text { years }\end{array}$ & $\begin{array}{l}\text { Cohort } 1: 7 \mathrm{pt} .(4 / 7 \mathrm{pt} . \\
\text { completed treatment })\end{array}$ & Cohort 1: Two doses (day 0 and day > 21) & $\begin{array}{l}\text { Subcutaneous } \\
\text { injection of IL-2 }\end{array}$ & [56] \\
\hline \multicolumn{6}{|l|}{ PRAME-Specific } \\
\hline NCT02743611 & n.d. & n.d. & $\begin{array}{l}\text { Escalating doses from } 1.25 \times 10^{6} \mathrm{~T} \text { cells } / \mathrm{kg} \\
\text { up to } 5 \times 10^{6} \mathrm{~T} \text { cells } / \mathrm{kg} \text { to be explored }\end{array}$ & $\begin{array}{l}\text { Rimiducid (in } \\
\text { response to } \\
\text { treatment-related } \\
\text { toxicity) }\end{array}$ & [57] \\
\hline $\begin{array}{c}\text { NCT03503968 } \\
\text { EudraCT-2017-000440-18 }\end{array}$ & n.d. & n.d. & $\begin{array}{l}\text { Cohort } 1 \text { : target dose of } 1 \times 10^{5} \mathrm{~T} \text { cells } / \mathrm{kg} \\
\text { Cohort } 2 \text { : target dose of } 1 \times 10^{6} \mathrm{~T} \text { cells } / \mathrm{kg} \\
\text { Cohort 3: target dose of } 5 \times 10^{6} \mathrm{~T} \text { cells } / \mathrm{kg} \\
\text { Optional cohort } 4 \text { : up to } 1 \times 10^{7} \mathrm{~T} \text { cells } / \mathrm{kg}\end{array}$ & n.d. & n.d. \\
\hline EudraCT-2018-000717-20 & n.d. & n.d. & $\begin{array}{c}\text { Patients that were treated with MDG1011 } \\
\text { TCR-T-cell product in } \\
\text { EudraCT-2017-000440-18 trial }\end{array}$ & n.d. & n.d. \\
\hline
\end{tabular}


Table 3. Cont.

\begin{tabular}{|c|c|c|c|c|c|}
\hline $\begin{array}{l}\text { Clinical Trial } \\
\text { Identifier }\end{array}$ & Age of Patients & $\begin{array}{l}\text { No. Patients per } \\
\text { Arm or Cohort }\end{array}$ & Dosage per Cohort & $\begin{array}{l}\text { Additional } \\
\text { Treatments }\end{array}$ & Ref. \\
\hline \multicolumn{6}{|l|}{ MiHA HA-1H-Specific } \\
\hline $\begin{array}{l}\text { EudraCT-2010-024625-20 } \\
\text { NTR3454/NL3307 }\end{array}$ & $\begin{array}{l}4 \text { pt. } 18-64 \text { years } \\
1 \text { pt. } \geq 65 \text { years }\end{array}$ & $\begin{array}{l}\text { Cohort 1: } 5 \text { pt. (4 AML } \\
\text { and } 1 \text { B-LBL) }\end{array}$ & $\begin{array}{l}\text { Cohort 1: two doses of } \geq 3 \times 10^{6} \mathrm{~T} \text { cells } \\
\quad(\text { day } 8 \text { and } 14 \text { after allo-HSCT) }\end{array}$ & n.d. & {$[49,58]$} \\
\hline $\begin{array}{c}\text { NCT04464889 } \\
\text { EudraCT-2019-002346-20 }\end{array}$ & n.d. & n.d. & $\begin{array}{l}\text { Cohort 1: target dose of } 0.3 \times 10^{6} \mathrm{~T} \text { cells } / \mathrm{kg} \\
\text { Cohort 2: target dose of } 1 \times 10^{6} \mathrm{~T} \text { cells } / \mathrm{kg} \\
\text { Cohort } 3 \text { : target dose of } 3 \times 10^{6} \mathrm{~T} \text { cells } / \mathrm{kg}\end{array}$ & n.d. & n.d. \\
\hline NCT03326921 & n.d. & n.d. & n.d. & n.d. & n.d. \\
\hline \multicolumn{6}{|l|}{ Other } \\
\hline NTR6541/NL6357 & n.d. & n.d. & n.d. & n.d. & [61-63] \\
\hline
\end{tabular}

Abbreviations: allo-HSCT, allogeneic hematopoietic stem cell transplantation; AML, acute myeloid leukemia; B-LBL, B-cell lymphoblastic leukemia; CML, chronic myeloid leukemia; HA-1H, HLA-A*02:01-restricted minor histocompatibility antigen 1 peptide variant H; IL-2, interleukin 2; MDS, myelodysplastic syndrome; MiHA, minor histocompatibility antigen; n.d., no data; PRAME, preferentially expressed antigen in melanoma; TKI, tyrosine kinase inhibitors; WT1, Wilms' tumor 1. Last search on 25 July 2021.

Table 4. Outcomes of clinical trials using TCR-T cells for AML.

\begin{tabular}{|c|c|c|c|c|c|}
\hline $\begin{array}{l}\text { Clinical Trial } \\
\text { Identifier }\end{array}$ & $\begin{array}{l}\text { Treatment-Related } \\
\text { Toxicities (Grade 1-2) }\end{array}$ & $\begin{array}{l}\text { Treatment-Related } \\
\text { Serious Adverse Events } \\
\text { (Grade 3-4) }\end{array}$ & $\begin{array}{l}\text { Persistence of } \\
\text { T Cells }\end{array}$ & Disease Response & Ref. \\
\hline \multicolumn{6}{|l|}{ WT1-Specific } \\
\hline $\begin{array}{l}\text { NCT01621724 } \\
\text { EudraCT-2006- } \\
\quad 004950-25\end{array}$ & No dose-limiting toxicity & $\begin{array}{l}\text { Cohort 1: febrile neutropenia } \\
\text { (1/3 pt.) }\end{array}$ & $\begin{array}{l}\text { Cohort } 1: 2 / 3 \mathrm{pt} . \\
\text { at day } 365 \\
\text { Cohort } 2: 2 / 4 \mathrm{pt} . \\
\text { at day } 365\end{array}$ & $\begin{array}{l}\text { Cohort } 1: \text { CR }(1 / 3 \mathrm{pt} .) \\
\text { no response }(2 / 3 \mathrm{pt} .) \\
\text { Cohort } 2: \text { CR }(3 / 4 \mathrm{pt} .) \\
\text { no response }(1 / 4 \mathrm{pt})\end{array}$ & [51] \\
\hline $\begin{array}{l}\text { NCT02550535 } \\
\text { EudraCT-2014- } \\
\text { 003111-10 }\end{array}$ & No dose-limiting toxicity & $\begin{array}{l}\text { Possibly treatment-related } \\
\text { cytokine release syndrome } \\
(1 / 10 \mathrm{pt} .)\end{array}$ & $\begin{array}{l}10 / 10 \text { pt. at day } 28 \\
7 / 10 \text { pt. at day } 29-365\end{array}$ & $\begin{array}{l}6 \text { AML pt.: median } \\
\text { survival of } 12 \text { months }\end{array}$ & {$[52,53]$} \\
\hline UMIN000011519 & $\begin{array}{l}\text { No dose-limiting toxicity } \\
\text { Facial edema, dermatitis, fever, } \\
\text { phlebitis, arrhythmia, } \\
\text { stomatitis }(1 / 8 \text { pt.) } \\
\text { Skin reaction at peptide } \\
\text { injection site }(7 / 8 \text { pt.) }\end{array}$ & None & $\begin{array}{l}\text { Cohort } 1: 2 / 3 \text { pt. } \\
\text { at day } 58 \\
\text { Cohort } 2: 3 / 5 \text { pt. } \\
\text { at day } 58\end{array}$ & $\begin{array}{c}\text { Decrease of abnormal } \\
\text { erythroblasts in PB (1/8 pt.); } \\
\text { Decrease of blasts in BM (2/8 pt.); } \\
\text { Stable disease (1/8 pt.); } \\
\text { Progressive disease (4/8 pt.) }\end{array}$ & [54] \\
\hline NCT01640301 & None disclosed & $\begin{array}{c}\text { Cytokine release syndrome } \\
(2 / 12 \mathrm{pt} .) \\
\text { Lymphopenia (12/12 pt.) } \\
\text { Trombocythopenia }(2 / 12 \mathrm{pt} .) \\
\text { Neutropenia }(2 / 12 \mathrm{pt} .) \\
\text { Anemia }(7 / 12 \mathrm{pt} .)\end{array}$ & $\begin{array}{l}9 / 12 \text { pt. at day } 28 \\
4 / 12 \text { pt. at day }>365\end{array}$ & $\begin{array}{l}\text { No evidence of disease (AML } \\
\text { recurrence) at median follow-up } \\
\text { of } 44 \text { months (12/12 pt.) }\end{array}$ & [55] \\
\hline NCT02770820 & $\begin{array}{l}\text { Not disclosed if treatment } \\
\text { related: Fatigue, alanine } \\
\text { aminotransferase increased, } \\
\text { hyperglycemia ( } 1 / 6 \text { pt.); } \\
\text { Anemia, thrombocytopenia } \\
\text { (2/6 pt.); Neutropenia, } \\
\text { leukopenia ( } 3 / 6 \text { pt.); } \\
\text { Hypertension ( } 4 / 6 \text { pt.); } \\
\text { Lymphopenia ( } 5 / 7 \text { pt.) }\end{array}$ & $\begin{array}{l}\text { Not disclosed if treatment } \\
\text { related: Death }(1 / 6 \mathrm{pt} .)\end{array}$ & n.d. & n.d. & [56] \\
\hline \multicolumn{6}{|l|}{ PRAME-Specific } \\
\hline NCT02743611 & \multicolumn{4}{|c|}{ No results available yet } & [57] \\
\hline $\begin{array}{l}\text { NCT03503968 } \\
\text { EudraCT-2017- } \\
\quad 000440-18\end{array}$ & \multicolumn{4}{|c|}{ No results available yet } & n.d. \\
\hline $\begin{array}{l}\text { EudraCT-2018- } \\
000717-20\end{array}$ & \multicolumn{4}{|c|}{ No results available yet } & n.d. \\
\hline \multicolumn{6}{|l|}{ MiHA HA-1H-Specific } \\
\hline $\begin{array}{c}\text { EudraCT-2010- } \\
\text { 024625-20 } \\
\text { NTR3454/NL3307 }\end{array}$ & None & None & $\begin{array}{l}3 / 5 \text { pt. at day } 14 \text { after } \\
\text { second infusion }\end{array}$ & $\begin{array}{l}\text { Relapsed AML prior to infusion } \\
\text { leading to death ( } 1 / 5 \text { pt.; } 1 / 4 \\
\text { AML pt.); Infections during } \\
\text { follow-up leading to death }(2 / 5 \\
\text { pt.; } \frac{1}{4} \text { AML pt.); No AML relapse } \\
\text { and alive ( } 2 / 4 \text { pt.) }\end{array}$ & {$[49,58]$} \\
\hline
\end{tabular}


Table 4. Cont.

\begin{tabular}{|c|c|c|c|c|}
\hline $\begin{array}{l}\text { Clinical Trial } \\
\text { Identifier }\end{array}$ & $\begin{array}{c}\text { Treatment-Related } \\
\text { Toxicities (Grade 1-2) }\end{array}$ & $\begin{array}{c}\text { Treatment-Related } \\
\text { Serious Adverse Events } \\
\text { (Grade 3-4) }\end{array}$ & Disease Response & Ref. \\
\hline $\begin{array}{l}\text { NCT04464889 } \\
\text { EudraCT-2019- } \\
\text { 002346-20 }\end{array}$ & & No results available yet & & n.d. \\
\hline $\begin{array}{l}\text { NCT03326921 } \\
\text { Other }\end{array}$ & & No results available yet & & n.d. \\
\hline NTR6541/NL6357 & & No results available yet & & [61-63] \\
\hline
\end{tabular}

Abbreviations: AML, acute myeloid leukemia; $\mathrm{BM}$, bone marrow; $\mathrm{CR}$, complete response; HA-1H, HLA-A*02:01-restricted minor histocompatibility antigen 1 peptide variant $\mathrm{H}$; MiHA, minor histocompatibility antigen; n.d., no data; PB, peripheral blood; PRAME, preferentially expressed antigen in melanoma; TCR, T-cell receptor; WT1, Wilms' tumor 1. Last search on 25 July 2021.

\section{Strategies for Enhancing TCR-T-Cell Products}

Some of the abovementioned clinical trials have used different strategies to optimize antigen recognition, TCR expression, and mechanisms to address potential safety concerns (Figure 2). Autologous T cells have been transduced with a codon-optimized WT1 $126-134$-specific TCR construct (NCT02550535) [52,53]. Codon optimization is a technique in which synonymous codons replace codons in coding sequences to improve protein translation rates and enhance protein expression. However, growing evidence indicates that, despite unaltering coding sequences, codon optimization may alter how proteins fold, thus impacting post-transcriptional modifications and protein functionality (reviewed by [64]). In the same study, TCR alpha and beta sequences were linked via a self-cleaving 2 A peptide derived from porcine teschovirus-1 $[52,53]$. Self-cleaving peptides, such as those from the foot-and-mouth disease virus or the abovementioned porcine teschovirus- 1 , allow the expression of multiple proteins using the same open reading frame [65]. On the one hand, this facilitates cell engineering, as only one vector has to be produced instead of one per sequence. On the other hand, it ensures stoichiometric independent expression of each protein. Nonetheless, careful design of sequences within the vector, including the selection of 2A peptides, the inclusion of additional spacers or furin sequences and the position of the sequences of genes of interest within the open reading frame, is key for correct protein production and function [66,67]. In the case of TCR expression, it has been observed that placing TCR alpha sequences downstream of $2 \mathrm{~A}$ peptide sequences is preferred [68]. Transgenic TCR expression was further improved in NCT02550535 by an additional disulfide bond between TCR alpha and beta chains [52,53]. This extra bond located within the extracellular domain of the TCR constant regions induces correct pairing of transgenic TCR chains and, therefore, avoids TCR mispairing between native and transgenic TCRs while retaining transgenic TCR functionality [69]. These techniques have also been exploited in other clinical trials (EudraCT-2010-024625-20 [49,59]; UMIN000011519 [54,70]; NCT02743611 [57]).

TCR affinity plays an essential role in TCR-T-cell avidity, which in turn is critical for the efficacy and clinical benefit of TCR-T-cell products [25]. Compared to affinity-matured TCRs, which can lead to supraphysiological affinities and fatal cross-reactivities [71], natural high-affinity TCRs recognize self-antigens within physiological conditions. However, T-cell clones of high affinity against self-TAAs, such as WT1 and PRAME, are usually eliminated after negative selection in the thymus, reducing the number of tumor-reactive TCRs that could be used in TCR-T-cell therapies. Those that remain, normally of low or intermediate affinity, usually promote inferior T-cell responses to physiological epitope densities, which would partly explain tumor immune escape [25]. Thus, high-affinity TCRs with better pMHC binding capabilities commonly generate better T-cell responses [25]. Techniques to enhance TCR affinity, e.g., artificial affinity maturation, have been developed to improve pMHC binding. TCR-T-cell trials for AML have capitalized on high-affinity HLAA*02:01-restricted TCRs directed against WT1 (NCT01640301 and NCT02770820) [55,56] and PRAME (NCT02743611) [57] (Figure 2). High-affinity WT1-specific TCRs were obtained from an HLA-A*02:01-positive individual (NCT01640301 and NCT02770820) [55,56]. 
Isolation of high-affinity TCRs from (healthy) donor repertoires is a laborious process, and artificial maturation of TCR affinity can lead to deleterious cross-reactivities. Therefore, an alternative is to isolate high-affinity allo-restricted TCRs from HLA-mismatched donors (Figure 2) [72]. In the context of AML therapy, allo-restricted TCRs have been used to recognize HLA-A*02:01-restricted $\mathrm{WT}_{126-134}$ peptide (NCT02550535) [52,53] and HLA-A*02:01-restricted PRAME peptides (NCT02743611) [57]. In another study, instead of a high-affinity $\alpha \beta T C R$, a high-affinity antigen-specific $\gamma \delta T C R$ was used (NTR6541) [61-63]. As mentioned previously, most studies focus on engineering conventional $\alpha \beta$ T cells with $\alpha \beta$ TCRs. However, unconventional $\gamma \delta$ TCRs derived from $\gamma \delta$ T cells are another source of tumor-specific TCRs (Figure 2). These $\gamma \delta$ TCRs are not HLA restricted and can be safely introduced in $\alpha \beta$ T cells instead of classical $\alpha \beta$ TCRs, since, as opposed to $\alpha \beta$ TCR gene transfer in $\alpha \beta$ T cells, mispairing between transgenic $\gamma \delta$ TCR chains and native $\alpha \beta$ TCR chains is unlikely due to preferential pairing $[73,74]$. With this approach, safety issues associated with mispaired $\alpha \beta$ TCR combinations formed from transgenic and native TCRs in TCR-engineered $\alpha \beta$ T cells are circumvented. Alternatively, native TCR expression can be eliminated using small interfering RNAs (siRNAs) against native TCR sequences (UMIN000011519; Figure 2) [54]. Short hairpin RNAs (shRNAs) were included in the vector containing the HLA-A*24:02-restricted WT1 235 -243-specific TCR construct to silence the expression of native TCRs and prevent TCR mispairing between native and transgenic TCR chains [54]. Transgenic TCR downregulation was prevented by codon optimization of the TCR sequence. Currently, other techniques such as CRISPR-Cas9 are gaining momentum in TCR-T-cell therapies to completely disrupt native TCR expression or even replace native TCR sequences with transgenic TCR sequences [75-77]. Recently, results from a phase I trial using CRISPR-Cas9-mediated disruption of native TCR and programmed cell death 1 (PD-1) sequences in combination with transduction of a TCR targeting cancer-testis antigen New York esophageal squamous cell carcinoma 1 (NY-ESO-1) have shown that this technique is feasible and safe (NCT03399448) [78]. However, this form of native TCR disruption has yet to be investigated for AML.

Other clinical studies benefit from donor-derived virus-specific T cells for TCR transduction, such as EBV and CMV-specific T cells (Figure 2, NCT01640301, NCT02770820, and EudraCT-2010-024625-20) [49,55,56,58]. These T-cell subsets can be commonly isolated, reduce the possibility of graft-versus-host disease (GVHD) by an endogenous TCR, and are naturally enriched for central memory $\mathrm{T}$ cells with enhanced in vivo persistence [55]. However, to circumvent the issue of low numbers of CMV seropositive patients, only EBVspecific T cells were used in NCT01640301 and NCT02770820 trials [55,56]. In these two studies, EBV-specific T cells were transduced with a high-affinity WT1-specific TCR derived from HLA-A*02:01-positive healthy donor repertoires [55]. In all current TCR-T clinical trials for AML, T cells are genetically engineered via viral transduction. This technique enables the stable expression of introduced TCRs, which raises concerns about potential insertional mutagenesis and persistent adverse effects caused by the stably engineered TCR-T cells. Results from a recent report in which investigators characterized the genomic integration profile of TEG001 following retroviral transduction showed that this approach does not induce malignant transformation of engineered T cells [79]. However, to address potential safety issues, such as insertional mutagenesis and off-target and on-target offtumor reactivities, safety mechanisms that can be induced in case of severe toxicities have been introduced in some TCR-T-cell clinical trials (NCT02743611, NCT03326921) [57]. These mechanisms are based on engineering $\mathrm{T}$ cells with suicide genes, such as inducible human caspase-9 (iC9; Figure 2). This protein is a key initiator of apoptosis and is activated after dimerization. Activation of iC9 can be induced following administration of rimiducid, a chemical compound that induces iC9 dimerization, thus inducing apoptosis in TCR-T cells. This system is not exclusive to TCR-T-cell therapies and can also be used in cases of haploidentical HSCT with alloreplete haploidentical T cells for AML treatment [80]. In this setting, administered haploidentical $\mathrm{T}$ cells promote immune reconstitution in patients, while the iC9 system can eliminate the administered T cells in the case of GVHD [80]. 
Alternatively, the aforementioned CRISPR-Cas9 and other approaches, such as those based on RNA or transposon/transposase systems, which are not per se viral vector-based engineering systems, may be used to replace viral transduction. However, CRISPR-Cas9 and transposon/transposase systems also entail genome editing, similar to viral transduction. In contrast, RNA-based systems, in which transgenic TCR-encoding mRNA is transfected into T cells alone or in combination with siRNA-mediated downregulation of native TCR, represent a transient self-limiting approach with a potentially better safety profile [81-83]. Nonetheless, despite extensive preclinical data, these techniques are still emerging in the clinical setting.

\section{Future Directions in TCR-T-Cell Therapy for AML}

Preliminary results indicate that TCR-T therapies for AML are safe and TCR-T cells can persist in most patients. Promising clinical data suggest that this form of therapy may also be efficacious in preventing relapse in AML patients. However, completed and ongoing trials have faced some limitations (Table 5). In two instances, investigators were not able to recruit a sufficient number of patients, whereas, in two other cases, planned TCR-T-cell numbers for administration were not achieved. Moreover, in the clinical trial EudraCT-2010-024625-20, the low efficacy of the HA-1H-specific T-cell product observed in treated patients led to the early termination of the study. Therefore, results from ongoing trials from which no results are available will provide more information about the benefit of TCR-T-cell therapy in this context.

Table 5. Limitations of clinical trials using TCR-T cells for AML.

\begin{tabular}{|c|c|}
\hline Clinical Trial Identifier & Description of Limitations \\
\hline \multicolumn{2}{|l|}{ WT1-Specific } \\
\hline $\begin{array}{l}\text { NCT01621724 } \\
\text { EudraCT-2006-004950-25 }\end{array}$ & $\begin{array}{l}\text { Enrolment into the study was terminated early due to difficulties in the } \\
\text { recruitment of patients }\end{array}$ \\
\hline $\begin{array}{l}\text { NCT02550535 } \\
\text { EudraCT-2014-003111-10 }\end{array}$ & $\begin{array}{l}\text { Enrolment into the study was terminated early in Germany due to difficulties in } \\
\text { the recruitment of patients }\end{array}$ \\
\hline UMIN000011519 & $\begin{array}{l}\text { T-cell numbers for Arm } 2 \text { were not feasible for all patients; T-cell products were } \\
\text { not feasible for Arm } 3\end{array}$ \\
\hline NCT01640301 & None disclosed \\
\hline NCT02770820 & None disclosed \\
\hline \multicolumn{2}{|l|}{ PRAME-Specific } \\
\hline NCT02743611 & n.d. \\
\hline NCT03503968/EudraCT-2017-000440-18 & n.d. \\
\hline EudraCT-2018-000717-20 & n.d. \\
\hline \multicolumn{2}{|l|}{ MiHA HA-1H-Specific } \\
\hline $\begin{array}{l}\text { EudraCT-2010-024625-20 } \\
\text { NTR3454/NL3307 }\end{array}$ & $\begin{array}{l}\text { HA-1H TCR-transduced CMV or EBV-specific T-cell products could not be } \\
\text { generated for } 4 \text { out of } 9 \text { patients; TCR-T cells could not be detected (lack of } \\
\text { TCR-T-cell expansion) in peripheral blood in } 2 \text { out of } 5 \text { treated patients at any time } \\
\text { during follow-up; } 3 \text { out of } 5 \text { treated patients died during follow-up for causes not } \\
\text { related to treatment; overall feasibility and efficacy of the procedure was too low to } \\
\text { warrant further developments of this therapy }\end{array}$ \\
\hline NCT04464889/EudraCT-2019-002346-20 & n.d. \\
\hline NCT03326921 & n.d. \\
\hline \multicolumn{2}{|l|}{ Other } \\
\hline NTR6541/NL6357 & n.d. \\
\hline
\end{tabular}

Abbreviations: AML, acute myeloid leukemia; CMV, cytomegalovirus; EBV, Epstein-Barr virus; HA-1H, HLA-A*02:01-restricted minor histocompatibility antigen 1 peptide variant $\mathrm{H}$; MiHA, minor histocompatibility antigen; n.d., no data; PRAME, preferentially expressed antigen in melanoma; TCR, T-cell receptor; WT1, Wilms' tumor 1. Last search on 25 July 2021. 
Multiple antigens for AML have been described over the years that have yet to be explored in the clinical setting as target antigens in TCR-T-cell therapy [7,8]. For some of these antigens, preclinical and clinical data hinted at their potential role as targets for TCR-T-cell therapy, including proteinase 3 (PR3), hyaluronan-mediated motility receptor (HMMR), and T-cell receptor $\gamma$ chain alternate reading frame protein (TARP). Together with WT1 and PRAME, PR3 is an AML-associated antigen overexpressed in AML blasts [36,84]. These antigens are differentially expressed in leukemic stem cells (LSCs) compared to hematopoietic stem cells; however, PR3 diverged from the other antigens analyzed in that it was comparatively more expressed on bulk leukemic cells rather than LSC [85]. Cytotoxic T-cell responses against PR3 are spontaneously detected in AML patients [40] and after PR1 vaccination [86,87]. PR1 is a nonameric HLA-A*02:01-restricted peptide derived from PR3 and neutrophil elastase (NE) that is commonly found to be overexpressed in AML [88]. PR3specific T-cell activity has also been observed after allo-HSCT [89-91], although in this case, LAA-specific T cells are difficult to detect in early phases after transplantation [92]. Results from clinical trials using allo-HSCT demonstrated that donor T cells mediate PR3-directed anti-AML responses, including in treated R/R AML patients $[89,90]$. Nonetheless, cytotoxic T-cell responses against PR3 were characterized by low-affinity interactions against this selfantigen [89]. Moreover, administration of PR1-specific bulk T cells into an AML xenograft NOD/SCID mouse model led to the reduction of human AML cells in mice [93]. Despite the aforementioned encouraging data, to the best of our knowledge, no TCRs have been isolated from PR1-specific T-cell clones and used in TCR-T-cell therapies. Current strategies targeting PR3 in the context of HLA-A2 restriction are mostly based on anti-PR1/HLAA2 antibodies [94,95], including bi-specific antibodies [96] and TCR-like CARs [97]. This warrants the potential of this antigen in fighting AML using TCR engineered T cells.

Greiner and colleagues defined HMMR, also known as RHAMM or CD168, as an immunogenic AML-associated antigen that could be targeted in immunotherapies [98]. Initially considered a promising antigen expressed in blasts in a considerable number of AML patients, HMMR expression was associated with poor overall survival and, therefore, also considered a potential prognostic factor [99]. DCs transfected with HMMR-encoding mRNA elicited HMMR-specific TCR responses [100]. However, the upregulation of HMMR via mRNA transfection showed no additional benefit compared to unmodified cells, as DCs presented basal HMMR expression levels to sufficiently activate T cells. T-cell reactivities against HMMR's R3 peptide have been detected in AML patients after standard of care [101-103], including after HMMR-R3 peptide vaccination [104,105]. However, in some cases, HMMR-specific T cells were non-functional [103]. T cells modified to express HMMRspecific TCRs were able to recognize AML target cells in a humanized xenograft mouse model leading to reduced tumor burden [106]. The addition of IL-15 further enhanced the antitumor effect of TCR-T cells. However, HMMR-specific TCR-T cells also recognized hematopoietic stem cells (HSCs), which restricted the use of these cells to MHC-mismatched HSC transplantation. In addition, Snauwaert and colleagues pointed out that HMMR may not be suitable as a candidate antigen in AML due to similar expression levels of HMMR in LSCs and hematopoietic stem cells in healthy individuals and its upregulation in activated T cells [107]. Therefore, the further development of HMMR-specific TCR-T-cell therapies seems unlikely. With regards to TARP, this antigen is upregulated in AML cell lines and de novo pediatric and adult AML cells [108]. Moreover, overexpression of an alternative TARP transcript is specific to AML, being absent in other types of leukemia, such as B-ALL and CML cells [108]. More importantly, TARP-specific TCR-T cells exert cytotoxic activity against TARP-positive AML cell lines and primary cells [108]. Other reports suggest other candidates for TCR-T-cell immunotherapy in AML, such as myeloperoxidase (MPO) [109] or human telomerase reverse transcriptase (hTERT) [110]. In these two cases, high-avidity TCRs were used.

Due to difficulties in isolating high-affinity/high-avidity TCRs for self-antigens, such as those mentioned above, novel target antigens are required. Donor T cells in HSCT can mediate both GVHD and GVL effects. The capacity of these $\mathrm{T}$ cells to recognize 
mismatched HLA molecules makes them a valuable tool in TCR-T therapy for relapsed patients after allo-HSCT. Similar to HA-1 antigen, HLA-DPB1-reactive T cells have been described as potent GVL inducers [111,112]. To prevent recurrent disease after allogeneic HSCT, T cells engineered with TCRs against HLA-DPB1 antigens, which are mismatched in many allogeneic transplantations, recognized AML cells in vitro; however, only TCRengineered CD4 T cells were able to effectively mediate leukemic elimination in vivo [113]. Extensive screening and validation of TCRs seem critical in this context to avoid targeting HLA-DP antigens that are also expressed on healthy tissues that could lead to undesirable GVHD [113]. In some cases, due to genetic aberrations that are characteristic of AML, new point mutations may occur in specific genes leading to the formation of neoantigens that the immune system can target more efficiently than self-antigens. An example of a neoantigen in AML is the CBFB-MYH11 fusion protein. A recent report showed that HLA-B*40:01-restricted T-cell clones react with high avidity against a nonameric peptide from the CBFB-MYH11 fusion protein [114]. These T cells showed antitumor reactivity against AML cell lines and primary AML cells both in vitro and in vivo in a humanized xenograft mouse model. Moreover, the introduction of TCRs derived from CBFB-MYH11specific T-cell clones showed anti-leukemic activity in vitro. T-cell responses have also been observed against nucleophosmin 1 (NPM1) mutations, which occur in approximately $30 \%$ of AML patients [115-117]. Isolation and transduction of an HLA-A*02:01-restricted mutated NPM1 peptide-specific TCR into T cells resulted in anti-AML activity in vivo [117]. Finally, the expression of inhibitory immune checkpoints in T cells is a factor to consider in TCR-T-cell therapy. The increased expression of immune checkpoints, such as programmed death 1 (PD-1), cytotoxic T-lymphocyte antigen 4 (CTLA4), T-cell immunoglobulin and mucin-domain containing-3 (TIM-3), and lymphocyte-activation gene 3 (LAG3), contribute to AML immune evasion and are associated with disease progression and relapse (reviewed by [118]). Thus, disruption of inhibitory receptors expressed by TCR-T cells and/or combinatorial immunotherapies based on TCR-T cells and immune checkpoint inhibitors (as seen in the combination of chemotherapy or hypomethylating agents) may pave the way for a higher efficacy and reduced immune evasion in the context of TCR-T-cell therapy for AML [119].

\section{Conclusions}

In summary, results from current clinical trials using TCR-T-cell therapy for AML indicate no treatment-related toxicities. This is achieved thanks to the careful selection of high-affinity TCRs derived from natural repertoires that do not rely on artificially enhancing TCR affinity above physiological levels. In terms of efficacy, it is too soon to draw conclusions from these studies, given their early phase design and the results from most of them being pending. However, preliminary results indicate that this type of therapy may be efficacious for AML, especially in cases of relapse, where remaining leukemic blasts may not be eliminated with the standard of care, warranting the development of improved TCR-T-cell strategies to further increase their clinical benefit.

Author Contributions: Conceptualization, D.C.-D.; writing-original draft preparation, D.C.-D.; writing-review and editing, S.A. and E.L.; visualization, D.C.-D.; supervision, E.L. All authors have read and agreed to the published version of the manuscript.

Funding: This research was supported by a "Cellular Immunotherapy" grant from the vzw Baillet Latour Fund (Belgium), and the Cellular Therapy Fund from the Antwerp University Hospital (UZA) Foundation. This work was supported in part by research grants of the Methusalem financing program of the Flemish Government to the Antwerp University and the Interuniversity Attraction Poles financing program of the Belgian Government. D.C.D. was supported by a DOCPRO4 Ph.D. grant from the Special Research Fund (BOF) of the University of Antwerp and by grant G053518N from the Research Fund-Flanders (FWO), Belgium). S.A. is a senior clinical investigator of the FWO (grant 1806220N). E.L. was supported by funds from FWO (grant T001216N) and Kom op tegen Kanker (KotK; grant KotK/2018/11465). 
Conflicts of Interest: The authors declare no conflict of interest. The funders had no role in the writing of the manuscript, or in the decision to publish the results.

\section{References}

1. Lipof, J.J.; Loh, K.P.; O’Dwyer, K.; Liesveld, J.L. Allogeneic Hematopoietic Cell Transplantation for Older Adults with Acute Myeloid Leukemia. Cancers 2018, 10, 179. [CrossRef]

2. Herold, T.; Rothenberg-Thurley, M.; Grunwald, V.V.; Janke, H.; Goerlich, D.; Sauerland, M.C.; Konstandin, N.P.; Dufour, A.; Schneider, S.; Neusser, M.; et al. Validation and refinement of the revised 2017 European LeukemiaNet genetic risk stratification of acute myeloid leukemia. Leukemia 2020, 34, 3161-3172. [CrossRef]

3. Schuurhuis, G.J.; Heuser, M.; Freeman, S.; Bene, M.C.; Buccisano, F.; Cloos, J.; Grimwade, D.; Haferlach, T.; Hills, R.K.; Hourigan, C.S.; et al. Minimal/measurable residual disease in AML: A consensus document from the European LeukemiaNet MRD Working Party. Blood 2018, 131, 1275-1291. [CrossRef]

4. Ngai, L.L.; Kelder, A.; Janssen, J.; Ossenkoppele, G.J.; Cloos, J. MRD Tailored Therapy in AML: What We Have Learned So Far. Front. Oncol. 2020, 10, 603636. [CrossRef]

5. Vago, L.; Gojo, I. Immune escape and immunotherapy of acute myeloid leukemia. J. Clin. Investig. 2020, 130, 1552-1564. [CrossRef]

6. Van Acker, H.H.; Versteven, M.; Lichtenegger, F.S.; Roex, G.; Campillo-Davo, D.; Lion, E.; Subklewe, M.; Van Tendeloo, V.F.; Berneman, Z.N.; Anguille, S. Dendritic Cell-Based Immunotherapy of Acute Myeloid Leukemia. J. Clin. Med. $2019,8,579$. [CrossRef] [PubMed]

7. Anguille, S.; Van Tendeloo, V.F.; Berneman, Z.N. Leukemia-associated antigens and their relevance to the immunotherapy of acute myeloid leukemia. Leukemia 2012, 26, 2186-2196. [CrossRef] [PubMed]

8. Daver, N.; Alotaibi, A.S.; Bucklein, V.; Subklewe, M. T-cell-based immunotherapy of acute myeloid leukemia: Current concepts and future developments. Leukemia 2021, 35, 1843-1863. [CrossRef] [PubMed]

9. Salter, A.I.; Pont, M.J.; Riddell, S.R. Chimeric antigen receptor-modified T cells: CD19 and the road beyond. Blood 2018, 131, 2621-2629. [CrossRef] [PubMed]

10. Timmers, M.; Roex, G.; Wang, Y.; Campillo-Davo, D.; Van Tendeloo, V.F.I.; Chu, Y.; Berneman, Z.N.; Luo, F.; Van Acker, H.H.; Anguille, S. Chimeric Antigen Receptor-Modified T-cell therapy in Multiple Myeloma: Beyond B Cell Maturation Antigen. Front. Immunol. 2019, 10, 1613. [CrossRef] [PubMed]

11. Holstein, S.A.; Lunning, M.A. CAR T-Cell Therapy in Hematologic Malignancies: A Voyage in Progress. Clin. Pharmacol. Ther. 2020, 107, 112-122. [CrossRef]

12. Mardiana, S.; Gill, S. CAR T Cells for Acute Myeloid Leukemia: State of the Art and Future Directions. Front. Oncol. 2020, 10, 697. [CrossRef]

13. Hofmann, S.; Schubert, M.L.; Wang, L.; He, B.; Neuber, B.; Dreger, P.; Muller-Tidow, C.; Schmitt, M. Chimeric Antigen Receptor (CAR) T-cell therapy in Acute Myeloid Leukemia (AML). J. Clin. Med. 2019, 8, 200. [CrossRef]

14. Acharya, U.H.; Walter, R.B. Chimeric Antigen Receptor (CAR)-Modified Immune Effector Cell Therapy for Acute Myeloid Leukemia (AML). Cancers 2020, 12, 3617. [CrossRef]

15. Ritchie, D.S.; Neeson, P.J.; Khot, A.; Peinert, S.; Tai, T.; Tainton, K.; Chen, K.; Shin, M.; Wall, D.M.; Honemann, D.; et al. Persistence and efficacy of second generation CAR T cell against the LeY antigen in acute myeloid leukemia. Mol. Ther. 2013, 21, 2122-2129. [CrossRef] [PubMed]

16. Cummins, K.D.; Gill, S. Chimeric antigen receptor T-cell therapy for acute myeloid leukemia: How close to reality? Haematologica 2019, 104, 1302-1308. [CrossRef] [PubMed]

17. Dao, T.; Yan, S.; Veomett, N.; Pankov, D.; Zhou, L.; Korontsvit, T.; Scott, A.; Whitten, J.; Maslak, P.; Casey, E.; et al. Targeting the intracellular WT1 oncogene product with a therapeutic human antibody. Sci. Transl. Med. 2013, 5, 176ra133. [CrossRef] [PubMed]

18. Tsimberidou, A.M.; Van Morris, K.; Vo, H.H.; Eck, S.; Lin, Y.F.; Rivas, J.M.; Andersson, B.S. T-cell receptor-based therapy: An innovative therapeutic approach for solid tumors. J. Hematol. Oncol. 2021, 14, 102. [CrossRef]

19. Biernacki, M.A.; Brault, M.; Bleakley, M. T-Cell Receptor-Based Immunotherapy for Hematologic Malignancies. Cancer J. 2019, 25, 179-190. [CrossRef] [PubMed]

20. Zhang, Y.; Li, Y. T cell receptor-engineered T cells for leukemia immunotherapy. Cancer Cell Int. 2019, 19, 2. [CrossRef]

21. Fisher, J.; Anderson, J. Engineering Approaches in Human Gamma Delta T Cells for Cancer Immunotherapy. Front. Immunol. 2018, 9, 1409. [CrossRef] [PubMed]

22. Van Acker, H.H.; Anguille, S.; Van Tendeloo, V.F.; Lion, E. Empowering gamma delta T cells with antitumor immunity by dendritic cell-based immunotherapy. Oncoimmunology 2015, 4, e1021538. [CrossRef] [PubMed]

23. Van Acker, H.H.; Anguille, S.; Willemen, Y.; Van den Bergh, J.M.; Berneman, Z.N.; Lion, E.; Smits, E.L.; Van Tendeloo, V.F. Interleukin-15 enhances the proliferation, stimulatory phenotype, and antitumor effector functions of human gamma delta $\mathrm{T}$ cells. J. Hematol. Oncol. 2016, 9, 101. [CrossRef]

24. Chandran, S.S.; Klebanoff, C.A. T cell receptor-based cancer immunotherapy: Emerging efficacy and pathways of resistance. Immunol. Rev. 2019, 290, 127-147. [CrossRef]

25. Campillo-Davo, D.; Flumens, D.; Lion, E. The Quest for the Best: How TCR Affinity, Avidity, and Functional Avidity Affect TCR-Engineered T-Cell Antitumor Responses. Cells 2020, 9, 1720. [CrossRef] 
26. Sugiyama, H. WT1 (Wilms' tumor gene 1): Biology and cancer immunotherapy. Jpn. J. Clin. Oncol. 2010, 40, 377-387. [CrossRef]

27. Drakos, E.; Rassidakis, G.Z.; Tsioli, P.; Lai, R.; Jones, D.; Medeiros, L.J. Differential expression of WT1 gene product in non-Hodgkin lymphomas. Appl. Immunohistochem. Mol. Morphol. 2005, 13, 132-137. [CrossRef]

28. Nakatsuka, S.; Oji, Y.; Horiuchi, T.; Kanda, T.; Kitagawa, M.; Takeuchi, T.; Kawano, K.; Kuwae, Y.; Yamauchi, A.; Okumura, M.; et al. Immunohistochemical detection of WT1 protein in a variety of cancer cells. Mod. Pathol. 2006, 19, 804-814. [CrossRef]

29. Menssen, H.D.; Renkl, H.J.; Rodeck, U.; Maurer, J.; Notter, M.; Schwartz, S.; Reinhardt, R.; Thiel, E. Presence of Wilms' tumor gene (wt1) transcripts and the WT1 nuclear protein in the majority of human acute leukemias. Leukemia 1995, 9, 1060-1067.

30. Niksic, M.; Slight, J.; Sanford, J.R.; Caceres, J.F.; Hastie, N.D. The Wilms' tumour protein (WT1) shuttles between nucleus and cytoplasm and is present in functional polysomes. Hum. Mol. Genet. 2004, 13, 463-471. [CrossRef] [PubMed]

31. Owen, C.; Fitzgibbon, J.; Paschka, P. The clinical relevance of Wilms Tumour 1 (WT1) gene mutations in acute leukaemia. Hematol. Oncol. 2010, 28, 13-19. [CrossRef] [PubMed]

32. Rampal, R.; Figueroa, M.E. Wilms tumor 1 mutations in the pathogenesis of acute myeloid leukemia. Haematologica 2016, 101, 672-679. [CrossRef] [PubMed]

33. Kumar, C.C. Genetic abnormalities and challenges in the treatment of acute myeloid leukemia. Genes Cancer 2011, 2, 95-107. [CrossRef]

34. Walker, A.; Marcucci, G. Molecular prognostic factors in cytogenetically normal acute myeloid leukemia. Expert Rev. Hematol. 2012, 5, 547-558. [CrossRef]

35. Epping, M.T.; Wang, L.; Edel, M.J.; Carlee, L.; Hernandez, M.; Bernards, R. The human tumor antigen PRAME is a dominant repressor of retinoic acid receptor signaling. Cell 2005, 122, 835-847. [CrossRef] [PubMed]

36. Steger, B.; Floro, L.; Amberger, D.C.; Kroell, T.; Tischer, J.; Kolb, H.J.; Schmetzer, H.M. WT1, PRAME, and PR3 mRNA Expression in Acute Myeloid Leukemia (AML). J. Immunother. 2020, 43, 204-215. [CrossRef]

37. Paydas, S.; Tanriverdi, K.; Yavuz, S.; Disel, U.; Baslamisli, F.; Burgut, R. PRAME mRNA levels in cases with acute leukemia: Clinical importance and future prospects. Am. J. Hematol. 2005, 79, 257-261. [CrossRef]

38. Ding, K.; Wang, X.M.; Fu, R.; Ruan, E.B.; Liu, H.; Shao, Z.H. PRAME Gene Expression in Acute Leukemia and Its Clinical Significance. Cancer Biol. Med. 2012, 9, 73-76. [CrossRef]

39. Qin, Y.; Zhu, H.; Jiang, B.; Li, J.; Lu, X.; Li, L.; Ruan, G.; Liu, Y.; Chen, S.; Huang, X. Expression patterns of WT1 and PRAME in acute myeloid leukemia patients and their usefulness for monitoring minimal residual disease. Leuk. Res. 2009, 33, 384-390. [CrossRef]

40. Scheibenbogen, C.; Letsch, A.; Thiel, E.; Schmittel, A.; Mailaender, V.; Baerwolf, S.; Nagorsen, D.; Keilholz, U. CD8 T-cell responses to Wilms tumor gene product WT1 and proteinase 3 in patients with acute myeloid leukemia. Blood 2002, 100, 2132-2137. [CrossRef]

41. Dao, T.; Korontsvit, T.; Zakhaleva, V.; Jarvis, C.; Mondello, P.; Oh, C.; Scheinberg, D.A. An immunogenic WT1-derived peptide that induces $T$ cell response in the context of HLA-A*02:01 and HLA-A*24:02 molecules. Oncoimmunology 2017, 6, e1252895. [CrossRef] [PubMed]

42. Nguyen, T.H.; Tan, A.C.; Xiang, S.D.; Goubier, A.; Harland, K.L.; Clemens, E.B.; Plebanski, M.; Kedzierska, K. Understanding CD8(+) T-cell responses toward the native and alternate HLA-A*02:01-restricted WT1 epitope. Clin. Transl. Immunol. 2017, 6, e134. [CrossRef] [PubMed]

43. Matko, S.; Manderla, J.; Bonsack, M.; Schmitz, M.; Bornhauser, M.; Tonn, T.; Odendahl, M. PRAME peptide-specific CD8(+) T cells represent the predominant response against leukemia-associated antigens in healthy individuals. Eur. J. Immunol. 2018, 48, 1400-1411. [CrossRef]

44. Anguille, S.; Van de Velde, A.L.; Smits, E.L.; Van Tendeloo, V.F.; Juliusson, G.; Cools, N.; Nijs, G.; Stein, B.; Lion, E.; Van Driessche, A.; et al. Dendritic cell vaccination as postremission treatment to prevent or delay relapse in acute myeloid leukemia. Blood 2017, 130, 1713-1721. [CrossRef] [PubMed]

45. Rezvani, K.; Yong, A.S.; Tawab, A.; Jafarpour, B.; Eniafe, R.; Mielke, S.; Savani, B.N.; Keyvanfar, K.; Li, Y.; Kurlander, R.; et al. Ex vivo characterization of polyclonal memory CD8+ T-cell responses to PRAME-specific peptides in patients with acute lymphoblastic leukemia and acute and chronic myeloid leukemia. Blood 2009, 113, 2245-2255. [CrossRef] [PubMed]

46. Oostvogels, R.; Lokhorst, H.M.; Mutis, T. Minor histocompatibility Ags: Identification strategies, clinical results and translational perspectives. Bone Marrow Transplant. 2016, 51, 163-171. [CrossRef] [PubMed]

47. Marijt, W.A.; Heemskerk, M.H.; Kloosterboer, F.M.; Goulmy, E.; Kester, M.G.; van der Hoorn, M.A.; van Luxemburg-Heys, S.A.; Hoogeboom, M.; Mutis, T.; Drijfhout, J.W.; et al. Hematopoiesis-restricted minor histocompatibility antigens HA-1- or HA-2-specific T cells can induce complete remissions of relapsed leukemia. Proc. Natl. Acad. Sci. USA 2003, 100, $2742-2747$. [CrossRef]

48. Cai, J.; Lee, J.; Jankowska-Gan, E.; Derks, R.; Pool, J.; Mutis, T.; Goulmy, E.; Burlingham, W.J. Minor H antigen HA-1-specific regulator and effector CD8+ T cells, and HA-1 microchimerism, in allograft tolerance. J. Exp. Med. 2004, 199, 1017-1023. [CrossRef]

49. Van Balen, P.; Jedema, I.; van Loenen, M.M.; de Boer, R.; van Egmond, H.M.; Hagedoorn, R.S.; Hoogstaten, C.; Veld, S.A.J.; Hageman, L.; van Liempt, P.A.G.; et al. HA-1H T-Cell Receptor Gene Transfer to Redirect Virus-Specific T Cells for Treatment of Hematological Malignancies After Allogeneic Stem Cell Transplantation: A Phase 1 Clinical Study. Front. Immunol. 2020, 11, 1804. [CrossRef] 
50. Torikai, H.; Akatsuka, Y.; Miyauchi, H.; Terakura, S.; Onizuka, M.; Tsujimura, K.; Miyamura, K.; Morishima, Y.; Kodera, Y.; Kuzushima, K.; et al. The HLA-A*0201-restricted minor histocompatibility antigen HA-1H peptide can also be presented by another HLA-A2 subtype, A*0206. Bone Marrow Transplant. 2007, 40, 165-174. [CrossRef]

51. European Union Clinical Trials Register. WT1 TCR Gene Therapy for Leukaemia: A Phase I/II Safety and Toxicity StudyEudraCT 2006-004950-25. Available online: www.clinicaltrialsregister.eu/ctr-search/trial/2006-004950-25/results (accessed on 25 July 2021).

52. Morris, E.C.; Tendeiro-Rego, R.; Richardson, R.; Fox, T.A.; Sillito, F.; Holler, A.; Thomas, S.; Xue, S.-A.; Martínez-Dávila, I.A.; Nicholson, E.; et al. A Phase I Study Evaluating the Safety and Persistence of Allorestricted WT1-TCR Gene Modified Autologous T Cells in Patients with High-Risk Myeloid Malignancies Unsuitable for Allogeneic Stem Cell Transplantation. Blood 2019, 134, 1367. [CrossRef]

53. European Union Clinical Trials Register. A Single Arm Phase I/II Study of the Safety and Efficacy of Gene-modified WT1 TCR Therapy in Patients with Myelodysplastic Syndrome (MDS) or Acute Myeloid Leukaemia (AML) Who Have Failed to Achieve or Maintain an IWG Defined Response Following Hypomethylating Agent Therapy. Available online: www.clinicaltrialsregister.eu/ ctr-search/trial/2014-003111-10/results (accessed on 25 July 2021).

54. Tawara, I.; Kageyama, S.; Miyahara, Y.; Fujiwara, H.; Nishida, T.; Akatsuka, Y.; Ikeda, H.; Tanimoto, K.; Terakura, S.; Murata, M.; et al. Safety and persistence of WT1-specific T-cell receptor gene-transduced lymphocytes in patients with AML and MDS. Blood 2017, 130, 1985-1994. [CrossRef]

55. Chapuis, A.G.; Egan, D.N.; Bar, M.; Schmitt, T.M.; McAfee, M.S.; Paulson, K.G.; Voillet, V.; Gottardo, R.; Ragnarsson, G.B.; Bleakley, M.; et al. T cell receptor gene therapy targeting WT1 prevents acute myeloid leukemia relapse post-transplant. Nat. Med. 2019, 25, 1064-1072. [CrossRef]

56. U.S. National Library of Medicine. Laboratory-Treated (Central Memory/Naive) CD8+ T Cells in Treating Patients with Newly Diagnosed or Relapsed Acute Myeloid Leukemia. Available online: Clinicaltrials.gov/ct2/show/results/NCT02770820 (accessed on 25 July 2021).

57. Amir, A.L.; van der Steen, D.M.; van Loenen, M.M.; Hagedoorn, R.S.; de Boer, R.; Kester, M.D.; de Ru, A.H.; Lugthart, G.J.; van Kooten, C.; Hiemstra, P.S.; et al. PRAME-specific Allo-HLA-restricted T cells with potent antitumor reactivity useful for therapeutic T-cell receptor gene transfer. Clin. Cancer Res. 2011, 17, 5615-5625. [CrossRef]

58. Van Loenen, M.M.; de Boer, R.; van Liempt, E.; Meij, P.; Jedema, I.; Falkenburg, J.H.; Heemskerk, M.H. A Good Manufacturing Practice procedure to engineer donor virus-specific T cells into potent anti-leukemic effector cells. Haematologica 2014, 99, 759-768. [CrossRef]

59. Van Loenen, M.M.; de Boer, R.; Hagedoorn, R.S.; van Egmond, E.H.; Falkenburg, J.H.; Heemskerk, M.H. Optimization of the HA-1-specific T-cell receptor for gene therapy of hematologic malignancies. Haematologica 2011, 96, 477-481. [CrossRef]

60. Styczynski, J.; Tridello, G.; Gil, L.; Ljungman, P.; Hoek, J.; Iacobelli, S.; Ward, K.N.; Cordonnier, C.; Einsele, H.; Socie, G.; et al. Impact of Donor Epstein-Barr Virus Serostatus on the Incidence of Graft-Versus-Host Disease in Patients With Acute Leukemia After Hematopoietic Stem-Cell Transplantation: A Study From the Acute Leukemia and Infectious Diseases Working Parties of the European Society for Blood and Marrow Transplantation. J. Clin. Oncol. 2016, 34, 2212-2220. [CrossRef] [PubMed]

61. Straetemans, T.; Kierkels, G.J.J.; Doorn, R.; Jansen, K.; Heijhuurs, S.; Dos Santos, J.M.; van Muyden, A.D.D.; Vie, H.; Clemenceau, B.; Raymakers, R.; et al. GMP-Grade Manufacturing of T Cells Engineered to Express a Defined gammadeltaTCR. Front. Immunol. 2018, 9, 1062. [CrossRef]

62. Grunder, C.; van Dorp, S.; Hol, S.; Drent, E.; Straetemans, T.; Heijhuurs, S.; Scholten, K.; Scheper, W.; Sebestyen, Z.; Martens, A.; et al. gamma9 and delta2CDR3 domains regulate functional avidity of T cells harboring gamma9delta2TCRs. Blood 2012, 120, 5153-5162. [CrossRef] [PubMed]

63. Johanna, I.; Straetemans, T.; Heijhuurs, S.; Aarts-Riemens, T.; Norell, H.; Bongiovanni, L.; de Bruin, A.; Sebestyen, Z.; Kuball, J. Evaluating in vivo efficacy-Toxicity profile of TEG001 in humanized mice xenografts against primary human AML disease and healthy hematopoietic cells. J. Immunother. Cancer 2019, 7, 69. [CrossRef] [PubMed]

64. Mauro, V.P. Codon Optimization in the Production of Recombinant Biotherapeutics: Potential Risks and Considerations. BioDrugs 2018, 32, 69-81. [CrossRef]

65. Szymczak, A.L.; Workman, C.J.; Wang, Y.; Vignali, K.M.; Dilioglou, S.; Vanin, E.F.; Vignali, D.A. Correction of multi-gene deficiency in vivo using a single 'self-cleaving' 2A peptide-based retroviral vector. Nat. Biotechnol. 2004, 22, 589-594. [CrossRef]

66. Hadpech, S.; Jinathep, W.; Saoin, S.; Thongkum, W.; Chupradit, K.; Yasamut, U.; Moonmuang, S.; Tayapiwatana, C. Impairment of a membrane-targeting protein translated from a downstream gene of a "self-cleaving" T2A peptide conjunction. Protein Expr. Purif. 2018, 150, 17-25. [CrossRef]

67. Yang, S.; Cohen, C.J.; Peng, P.D.; Zhao, Y.; Cassard, L.; Yu, Z.; Zheng, Z.; Jones, S.; Restifo, N.P.; Rosenberg, S.A.; et al. Development of optimal bicistronic lentiviral vectors facilitates high-level TCR gene expression and robust tumor cell recognition. Gene Ther. 2008, 15, 1411-1423. [CrossRef]

68. Leisegang, M.; Engels, B.; Meyerhuber, P.; Kieback, E.; Sommermeyer, D.; Xue, S.A.; Reuss, S.; Stauss, H.; Uckert, W. Enhanced functionality of $\mathrm{T}$ cell receptor-redirected T cells is defined by the transgene cassette. J. Mol. Med. 2008, 86, 573-583. [CrossRef]

69. Cohen, C.J.; Li, Y.F.; El-Gamil, M.; Robbins, P.F.; Rosenberg, S.A.; Morgan, R.A. Enhanced antitumor activity of T cells engineered to express T-cell receptors with a second disulfide bond. Cancer Res. 2007, 67, 3898-3903. [CrossRef] [PubMed] 
70. Ochi, T.; Fujiwara, H.; Okamoto, S.; An, J.; Nagai, K.; Shirakata, T.; Mineno, J.; Kuzushima, K.; Shiku, H.; Yasukawa, M. Novel adoptive T-cell immunotherapy using a WT1-specific TCR vector encoding silencers for endogenous TCRs shows marked antileukemia reactivity and safety. Blood 2011, 118, 1495-1503. [CrossRef] [PubMed]

71. Linette, G.P.; Stadtmauer, E.A.; Maus, M.V.; Rapoport, A.P.; Levine, B.L.; Emery, L.; Litzky, L.; Bagg, A.; Carreno, B.M.; Cimino, P.J.; et al. Cardiovascular toxicity and titin cross-reactivity of affinity-enhanced T cells in myeloma and melanoma. Blood 2013, 122, 863-871. [CrossRef]

72. Wilde, S.; Geiger, C.; Milosevic, S.; Mosetter, B.; Eichenlaub, S.; Schendel, D.J. Generation of allo-restricted peptide-specific T cells using RNA-pulsed dendritic cells: A three phase experimental procedure. Oncoimmunology 2012, 1, 129-140. [CrossRef] [PubMed]

73. Van der Veken, L.T.; Hagedoorn, R.S.; van Loenen, M.M.; Willemze, R.; Falkenburg, J.H.; Heemskerk, M.H. Alphabeta T-cell receptor engineered gammadelta T cells mediate effective antileukemic reactivity. Cancer Res. 2006, 66, 3331-3337. [CrossRef]

74. Van der Veken, L.T.; Coccoris, M.; Swart, E.; Falkenburg, J.H.; Schumacher, T.N.; Heemskerk, M.H. Alpha beta T cell receptor transfer to gamma delta T cells generates functional effector cells without mixed TCR dimers in vivo. J. Immunol. 2009, 182, 164-170. [CrossRef]

75. Osborn, M.J.; Webber, B.R.; Knipping, F.; Lonetree, C.L.; Tennis, N.; DeFeo, A.P.; McElroy, A.N.; Starker, C.G.; Lee, C.; Merkel, S.; et al. Evaluation of TCR Gene Editing Achieved by TALENs, CRISPR/Cas9, and megaTAL Nucleases. Mol. Ther. 2016, 24, 570-581. [CrossRef]

76. Legut, M.; Dolton, G.; Mian, A.A.; Ottmann, O.G.; Sewell, A.K. CRISPR-mediated TCR replacement generates superior anticancer transgenic T cells. Blood 2018, 131, 311-322. [CrossRef]

77. Schober, K.; Muller, T.R.; Gokmen, F.; Grassmann, S.; Effenberger, M.; Poltorak, M.; Stemberger, C.; Schumann, K.; Roth, T.L.; Marson, A.; et al. Orthotopic replacement of T-cell receptor alpha- and beta-chains with preservation of near-physiological T-cell function. Nat. Biomed. Eng. 2019, 3, 974-984. [CrossRef]

78. Stadtmauer, E.A.; Fraietta, J.A.; Davis, M.M.; Cohen, A.D.; Weber, K.L.; Lancaster, E.; Mangan, P.A.; Kulikovskaya, I.; Gupta, M.; Chen, F.; et al. CRISPR-engineered T cells in patients with refractory cancer. Science 2020, 367, eaba7365. [CrossRef] [PubMed]

79. Straetemans, T.; Janssen, A.; Jansen, K.; Doorn, R.; Aarts, T.; van Muyden, A.D.D.; Simonis, M.; Bergboer, J.; de Witte, M.; Sebestyen, Z.; et al. TEG001 Insert Integrity from Vector Producer Cells until Medicinal Product. Mol. Ther. 2020, 28, 561-571. [CrossRef] [PubMed]

80. Zhou, X.; Dotti, G.; Krance, R.A.; Martinez, C.A.; Naik, S.; Kamble, R.T.; Durett, A.G.; Dakhova, O.; Savoldo, B.; Di Stasi, A.; et al. Inducible caspase-9 suicide gene controls adverse effects from alloreplete T cells after haploidentical stem cell transplantation. Blood 2015, 125, 4103-4113. [CrossRef] [PubMed]

81. Schaft, N.; Dorrie, J.; Muller, I.; Beck, V.; Baumann, S.; Schunder, T.; Kampgen, E.; Schuler, G. A new way to generate cytolytic tumor-specific T cells: Electroporation of RNA coding for a T cell receptor into T lymphocytes. Cancer Immunol. Immunother. 2006, 55, 1132-1141. [CrossRef] [PubMed]

82. Harrer, D.C.; Simon, B.; Fujii, S.I.; Shimizu, K.; Uslu, U.; Schuler, G.; Gerer, K.F.; Hoyer, S.; Dorrie, J.; Schaft, N. RNA-transfection of gamma/delta $\mathrm{T}$ cells with a chimeric antigen receptor or an alpha/beta T-cell receptor: A safer alternative to genetically engineered alpha/beta T cells for the immunotherapy of melanoma. BMC Cancer 2017, 17, 551. [CrossRef]

83. Campillo-Davo, D.; Fujiki, F.; Van den Bergh, J.M.J.; De Reu, H.; Smits, E.; Goossens, H.; Sugiyama, H.; Lion, E.; Berneman, Z.N.; Van Tendeloo, V. Efficient and Non-genotoxic RNA-Based Engineering of Human T Cells Using Tumor-Specific T Cell Receptors With Minimal TCR Mispairing. Front. Immunol. 2018, 9, 2503. [CrossRef] [PubMed]

84. Dengler, R.; Munstermann, U.; al-Batran, S.; Hausner, I.; Faderl, S.; Nerl, C.; Emmerich, B. Immunocytochemical and flow cytometric detection of proteinase 3 (myeloblastin) in normal and leukaemic myeloid cells. Br. J. Haematol. 1995, 89, $250-257$. [CrossRef] [PubMed]

85. Schneider, V.; Zhang, L.; Rojewski, M.; Fekete, N.; Schrezenmeier, H.; Erle, A.; Bullinger, L.; Hofmann, S.; Gotz, M.; Dohner, K.; et al. Leukemic progenitor cells are susceptible to targeting by stimulated cytotoxic T cells against immunogenic leukemia-associated antigens. Int. J. Cancer 2015, 137, 2083-2092. [CrossRef] [PubMed]

86. Rezvani, K.; Yong, A.S.; Mielke, S.; Savani, B.N.; Musse, L.; Superata, J.; Jafarpour, B.; Boss, C.; Barrett, A.J. Leukemia-associated antigen-specific T-cell responses following combined PR1 and WT1 peptide vaccination in patients with myeloid malignancies. Blood 2008, 111, 236-242. [CrossRef]

87. Qazilbash, M.H.; Wieder, E.; Thall, P.F.; Wang, X.; Rios, R.; Lu, S.; Kanodia, S.; Ruisaard, K.E.; Giralt, S.A.; Estey, E.H.; et al. PR1 peptide vaccine induces specific immunity with clinical responses in myeloid malignancies. Leukemia 2017, 31, 697-704. [CrossRef]

88. Molldrem, J.; Dermime, S.; Parker, K.; Jiang, Y.Z.; Mavroudis, D.; Hensel, N.; Fukushima, P.; Barrett, A.J. Targeted T-cell therapy for human leukemia: Cytotoxic T lymphocytes specific for a peptide derived from proteinase 3 preferentially lyse human myeloid leukemia cells. Blood 1996, 88, 2450-2457. [CrossRef]

89. Medina, D.J.; Gharibo, M.; Savage, P.; Cohler, A.; Kuriyan, M.; Balsara, B.; Anand, M.; Schaar, D.; Krimmel, T.; Saggiomo, K.; et al. A pilot study of allogeneic cellular therapy for patients with advanced hematologic malignancies. Leuk. Res. 2008, 32, $1842-1848$. [CrossRef] 
90. Kapp, M.; Stevanovic, S.; Fick, K.; Tan, S.M.; Loeffler, J.; Opitz, A.; Tonn, T.; Stuhler, G.; Einsele, H.; Grigoleit, G.U. CD8+ T-cell responses to tumor-associated antigens correlate with superior relapse-free survival after allo-SCT. Bone Marrow Transplant. 2009, 43, 399-410. [CrossRef]

91. Steger, B.; Milosevic, S.; Doessinger, G.; Reuther, S.; Liepert, A.; Braeu, M.; Schick, J.; Vogt, V.; Schuster, F.; Kroell, T.; et al. CD4(+)and CD8(+)T-cell reactions against leukemia-associated- or minor-histocompatibility-antigens in AML-patients after allogeneic SCT. Immunobiology 2014, 219, 247-260. [CrossRef]

92. Rucker-Braun, E.; Link, C.S.; Schmiedgen, M.; Tunger, A.; Vizjak, P.; Teipel, R.; Wehner, R.; Kuhn, D.; Fuchs, Y.F.; Oelschlagel, U.; et al. Longitudinal analyses of leukemia-associated antigen-specific CD8(+) T cells in patients after allogeneic stem cell transplantation. Exp. Hematol. 2016, 44, 1024-1033.e1021. [CrossRef]

93. Ma, Q.; Wang, C.; Jones, D.; Quintanilla, K.E.; Li, D.; Wang, Y.; Wieder, E.D.; Clise-Dwyer, K.; Alatrash, G.; Mj, Y.; et al. Adoptive transfer of PR1 cytotoxic T lymphocytes associated with reduced leukemia burden in a mouse acute myeloid leukemia xenograft model. Cytotherapy 2010, 12, 1056-1062. [CrossRef]

94. Sergeeva, A.; Alatrash, G.; He, H.; Ruisaard, K.; Lu, S.; Wygant, J.; McIntyre, B.W.; Ma, Q.; Li, D.; St John, L.; et al. An anti-PR1/HLA-A2 T-cell receptor-like antibody mediates complement-dependent cytotoxicity against acute myeloid leukemia progenitor cells. Blood 2011, 117, 4262-4272. [CrossRef]

95. Sergeeva, A.; He, H.; Ruisaard, K.; St John, L.; Alatrash, G.; Clise-Dwyer, K.; Li, D.; Patenia, R.; Hong, R.; Sukhumalchandra, P.; et al. Activity of 8F4, a T-cell receptor-like anti-PR1/HLA-A2 antibody, against primary human AML in vivo. Leukemia 2016, 30, 1475-1484. [CrossRef]

96. Herrmann, A.C.; Im, J.S.; Pareek, S.; Ruiz-Vasquez, W.; Lu, S.; Sergeeva, A.; Mehrens, J.; He, H.; Alatrash, G.; Sukhumalchandra, P.; et al. A Novel T-Cell Engaging Bi-specific Antibody Targeting the Leukemia Antigen PR1/HLA-A2. Front. Immunol. 2018, 9 , 3153. [CrossRef]

97. Ma, Q.; Garber, H.R.; Lu, S.; He, H.; Tallis, E.; Ding, X.; Sergeeva, A.; Wood, M.S.; Dotti, G.; Salvado, B.; et al. A novel TCR-like CAR with specificity for PR1/HLA-A2 effectively targets myeloid leukemia in vitro when expressed in human adult peripheral blood and cord blood T cells. Cytotherapy 2016, 18, 985-994. [CrossRef]

98. Greiner, J.; Ringhoffer, M.; Taniguchi, M.; Schmitt, A.; Kirchner, D.; Krahn, G.; Heilmann, V.; Gschwend, J.; Bergmann, L.; Dohner, $\mathrm{H}$; ; et al. Receptor for hyaluronan acid-mediated motility (RHAMM) is a new immunogenic leukemia-associated antigen in acute and chronic myeloid leukemia. Exp. Hematol. 2002, 30, 1029-1035. [CrossRef]

99. Tzankov, A.; Strasser, U.; Dirnhofer, S.; Menter, T.; Arber, C.; Jotterand, M.; Rovo, A.; Tichelli, A.; Stauder, R.; Gunthert, U. In situ RHAMM protein expression in acute myeloid leukemia blasts suggests poor overall survival. Ann. Hematol. 2011, 90, 901-909. [CrossRef] [PubMed]

100. Willemen, Y.; Van den Bergh, J.M.; Bonte, S.M.; Anguille, S.; Heirman, C.; Stein, B.M.; Goossens, H.; Kerre, T.; Thielemans, K.; Peeters, M.; et al. The tumor-associated antigen RHAMM (HMMR/CD168) is expressed by monocyte-derived dendritic cells and presented to T cells. Oncotarget 2016, 7, 73960-73970. [CrossRef] [PubMed]

101. Greiner, J.; Schmitt, M.; Li, L.; Giannopoulos, K.; Bosch, K.; Schmitt, A.; Dohner, K.; Schlenk, R.F.; Pollack, J.R.; Dohner, H.; et al. Expression of tumor-associated antigens in acute myeloid leukemia: Implications for specific immunotherapeutic approaches. Blood 2006, 108, 4109-4117. [CrossRef] [PubMed]

102. Greiner, J.; Li, L.; Ringhoffer, M.; Barth, T.F.; Giannopoulos, K.; Guillaume, P.; Ritter, G.; Wiesneth, M.; Dohner, H.; Schmitt, M. Identification and characterization of epitopes of the receptor for hyaluronic acid-mediated motility (RHAMM/CD168) recognized by CD8+ T cells of HLA-A2-positive patients with acute myeloid leukemia. Blood 2005, 106, 938-945. [CrossRef] [PubMed]

103. Casalegno-Garduno, R.; Meier, C.; Schmitt, A.; Spitschak, A.; Hilgendorf, I.; Rohde, S.; Hirt, C.; Freund, M.; Putzer, B.M.; Schmitt, M. Immune responses to RHAMM in patients with acute myeloid leukemia after chemotherapy and allogeneic stem cell transplantation. Clin. Dev. Immunol. 2012, 2012, 146463. [CrossRef] [PubMed]

104. Schmitt, M.; Schmitt, A.; Rojewski, M.T.; Chen, J.; Giannopoulos, K.; Fei, F.; Yu, Y.; Gotz, M.; Heyduk, M.; Ritter, G.; et al. RHAMM-R3 peptide vaccination in patients with acute myeloid leukemia, myelodysplastic syndrome, and multiple myeloma elicits immunologic and clinical responses. Blood 2008, 111, 1357-1365. [CrossRef] [PubMed]

105. Greiner, J.; Schmitt, A.; Giannopoulos, K.; Rojewski, M.T.; Gotz, M.; Funk, I.; Ringhoffer, M.; Bunjes, D.; Hofmann, S.; Ritter, G.; et al. High-dose RHAMM-R3 peptide vaccination for patients with acute myeloid leukemia, myelodysplastic syndrome and multiple myeloma. Haematologica 2010, 95, 1191-1197. [CrossRef] [PubMed]

106. Spranger, S.; Jeremias, I.; Wilde, S.; Leisegang, M.; Starck, L.; Mosetter, B.; Uckert, W.; Heemskerk, M.H.; Schendel, D.J.; Frankenberger, B. TCR-transgenic lymphocytes specific for HMMR/Rhamm limit tumor outgrowth in vivo. Blood 2012, 119, 3440-3449. [CrossRef] [PubMed]

107. Snauwaert, S.; Vanhee, S.; Goetgeluk, G.; Verstichel, G.; Van Caeneghem, Y.; Velghe, I.; Philippe, J.; Berneman, Z.N.; Plum, J.; Taghon, T.; et al. RHAMM/HMMR (CD168) is not an ideal target antigen for immunotherapy of acute myeloid leukemia. Haematologica 2012, 97, 1539-1547. [CrossRef]

108. Depreter, B.; Weening, K.E.; Vandepoele, K.; Essand, M.; De Moerloose, B.; Themeli, M.; Cloos, J.; Hanekamp, D.; Moors, I.; D'Hont, I.; et al. TARP is an immunotherapeutic target in acute myeloid leukemia expressed in the leukemic stem cell compartment. Haematologica 2020, 105, 1306-1316. [CrossRef] 
109. Klar, R.; Schober, S.; Rami, M.; Mall, S.; Merl, J.; Hauck, S.M.; Ueffing, M.; Admon, A.; Slotta-Huspenina, J.; Schwaiger, M.; et al. Therapeutic targeting of naturally presented myeloperoxidase-derived HLA peptide ligands on myeloid leukemia cells by TCR-transgenic T cells. Leukemia 2014, 28, 2355-2366. [CrossRef]

110. Sandri, S.; De Sanctis, F.; Lamolinara, A.; Boschi, F.; Poffe, O.; Trovato, R.; Fiore, A.; Sartori, S.; Sbarbati, A.; Bondanza, A.; et al. Effective control of acute myeloid leukaemia and acute lymphoblastic leukaemia progression by telomerase specific adoptive T-cell therapy. Oncotarget 2017, 8, 86987-87001. [CrossRef]

111. Ibisch, C.; Gallot, G.; Vivien, R.; Diez, E.; Jotereau, F.; Garand, R.; Vie, H. Recognition of leukemic blasts by HLA-DPB1-specific cytotoxic T cell clones: A perspective for adjuvant immunotherapy post-bone marrow transplantation. Bone Marrow Transplant. 1999, 23, 1153-1159. [CrossRef]

112. Herr, W.; Eichinger, Y.; Beshay, J.; Bloetz, A.; Vatter, S.; Mirbeth, C.; Distler, E.; Hartwig, U.F.; Thomas, S. HLA-DPB1 mismatch alleles represent powerful leukemia rejection antigens in CD4 T-cell immunotherapy after allogeneic stem-cell transplantation. Leukemia 2017, 31, 434-445. [CrossRef]

113. Klobuch, S.; Hammon, K.; Vatter-Leising, S.; Neidlinger, E.; Zwerger, M.; Wandel, A.; Neuber, L.M.; Heilmeier, B.; Fichtner, R.; Mirbeth, C.; et al. HLA-DPB1 Reactive T Cell Receptors for Adoptive Immunotherapy in Allogeneic Stem Cell Transplantation. Cells 2020, 9, 1264. [CrossRef]

114. Biernacki, M.A.; Foster, K.A.; Woodward, K.B.; Coon, M.E.; Cummings, C.; Cunningham, T.M.; Dossa, R.G.; Brault, M.; Stokke, J.; Olsen, T.M.; et al. CBFB-MYH11 fusion neoantigen enables T cell recognition and killing of acute myeloid leukemia. J. Clin. Investig. 2020, 130, 5127-5141. [CrossRef] [PubMed]

115. Greiner, J.; Ono, Y.; Hofmann, S.; Schmitt, A.; Mehring, E.; Gotz, M.; Guillaume, P.; Dohner, K.; Mytilineos, J.; Dohner, H.; et al. Mutated regions of nucleophosmin 1 elicit both CD4(+) and CD8(+) T-cell responses in patients with acute myeloid leukemia. Blood 2012, 120, 1282-1289. [CrossRef] [PubMed]

116. Forghieri, F.; Riva, G.; Lagreca, I.; Barozzi, P.; Vallerini, D.; Morselli, M.; Paolini, A.; Bresciani, P.; Colaci, E.; Maccaferri, M.; et al. Characterization and dynamics of specific T cells against nucleophosmin-1 (NPM1)-mutated peptides in patients with NPM1-mutated acute myeloid leukemia. Oncotarget 2019, 10, 869-882. [CrossRef]

117. Van der Lee, D.I.; Reijmers, R.M.; Honders, M.W.; Hagedoorn, R.S.; de Jong, R.C.; Kester, M.G.; van der Steen, D.M.; de Ru, A.H.; Kweekel, C.; Bijen, H.M.; et al. Mutated nucleophosmin 1 as immunotherapy target in acute myeloid leukemia. J. Clin. Investig. 2019, 129, 774-785. [CrossRef] [PubMed]

118. Hobo, W.; Hutten, T.J.A.; Schaap, N.P.M.; Dolstra, H. Immune checkpoint molecules in acute myeloid leukaemia: Managing the double-edged sword. Br. J. Haematol. 2018, 181, 38-53. [CrossRef]

119. Stahl, M.; Goldberg, A.D. Immune Checkpoint Inhibitors in Acute Myeloid Leukemia: Novel Combinations and Therapeutic Targets. Curr. Oncol. Rep. 2019, 21, 37. [CrossRef] [PubMed] 